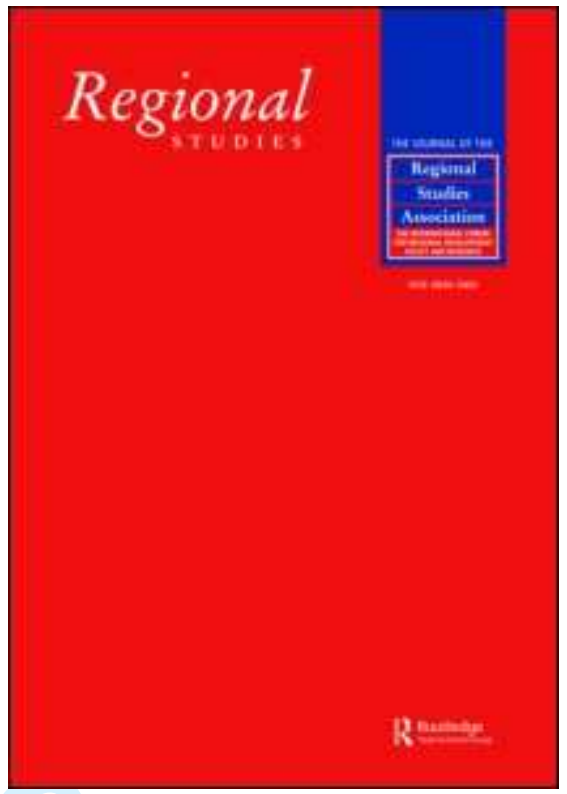

\title{
THE EMERGENCE OF NOVEL SCIENCE-RELATED FIELDS: \\ REGIONAL OR TECHNOLOGICAL PATTERNS? \\ EXPLORATION AND EXPLOITATION IN UK NANOTECHNOLOGY
}

\begin{tabular}{|r|l|}
\hline Journal: & Regional Studies \\
\hline Manuscript ID: & CRES-2007-0288.R3 \\
\hline Manuscript Type: & Main Section \\
\hline JEL codes: & $\begin{array}{l}\text { O31 - Innovation and Invention: Processes and Incentives < O3 - } \\
\text { Technological Change|Research and Development < O - Economic } \\
\text { Development, Technological Change, and Growth, O33 - } \\
\text { Technological Change: Choices and Consequences|Diffusion } \\
\text { Processes < O3 - Technological Change|Research and Development } \\
\text { O38 - Government Policy < O3 - Technological Change|Research } \\
\text { and Development < O - Economic Development, Technological } \\
\text { Change, and Growth, O52 - Europe < O5 - Economywide Country } \\
\text { Studies < O - Economic Development, Technological Change, and } \\
\text { Growth }\end{array}$ \\
\hline Keywords: & $\begin{array}{l}\text { patent analysis, bibliometrics, innovation systems, emerging } \\
\text { technologies, nano-districts }\end{array}$ \\
\hline
\end{tabular}




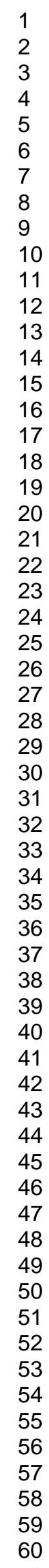

5.) ShholaroNE" $_{\text {Manuscript Central }}$

7

10

11
12

13

14

15

16

18

19

20

22

23

25

26

27

29

30

32

33

34

35

36

$(37$

39

40

41

43

44

45

46

47

48

50

51

52

53

54

56

57

58

60

http://mc.manuscriptcentral.com/cres Email: regional.studies@fm.ru.nl 


\title{
THE EMERGENCE OF NOVEL SCIENCE-RELATED FIELDS: REGIONAL OR TECHNOLOGICAL PATTERNS? \\ EXPLORATION AND EXPLOITATION IN UK NANOTECHNOLOGY
}

\author{
Martin Meyer ${ }^{1}$ \\ Department of Business and Management, \\ School of Business, Management and Economics, \\ University of Sussex, \\ Brighton BN1 9RH, \\ United Kingdom \\ and \\ Centre for R\&D Monitoring (ECOOM), \\ KU Leuven, \\ Dekenstraat 2, \\ 3000 Leuven, \\ Belgium \\ Tel.: +44 1273877978 \\ e-mail: $\underline{\text { m.s.meyer@sussex.ac.uk }}$
}

\author{
Dirk Libaers \\ Institute of Entrepreneurship and Innovation, \\ University of Missouri - Kansas City \\ Kansas City, MO 64110 \\ United States \\ Tel.: +1-816-235-2625 \\ e-mail: libaersd@umkc.edu \\ Jae-Hwan Park \\ Institute for Manufacturing, \\ University of Cambridge, \\ Cambridge CB3 OFS, \\ United Kingdom \\ Tel.: $+44(0) 1223766141$ \\ E-mail: jhp37@cam.ac.uk
}

(Received September 2007: in revised form February 2010)

${ }^{1}$ Corresponding author 
Abstract:

An extensive literature addresses the emergence of new technologies in their geographical and cognitive context. Drawing on a spatial innovation systems approach, our paper explores this issue for a newly emerging area, nano-science and nanotechnology. This study draws on a multimethod approach to explore the emergence of nanotechnology in the UK, covering bibliometric, patent and firm-level data. Our results point to regional concentrations of scientific and technological activity as well as a concentration of nanotechnology firms in the well-established 'science hubs'. However, further inspection of the evidence hints also at the importance of non-local links and networks along technological paths.

Keywords: patent analysis, bibliometrics, innovation systems, emerging technologies, nanodistricts

JEL codes: $031,033,038,052$ 


\section{Introduction}

This article addresses the emergence of new technologies in their geographical and cognitive context. Technological innovation patterns can be analysed using a number of levels and units of analysis, each highlighting differing aspects of the boundaries of and the activities and interactions within innovation systems that initiate, import, modify and diffuse novel technologies (Freeman, 1987). An extensive literature has evolved that addresses the emergence of new technologies in their geographical and cognitive context. The notion of innovation systems has been most prominent in these discussions (e.g. Nelson, 1993; Lundvall et al., 2002; Edquist, 2005a,b). Edquist (2005b: 182) offers a definition of a generic system of innovation as "all important economic, social, political, organizational, institutional, and other factors that influence the development, diffusion and use of innovations." Every system has a limited extension. The boundaries of the system can be spatial, sectoral, or technological.

Within the overall framework, there have been pronounced differences between approaches as to whether the emergence of technologies occurs predominantly in a spatial (regional, national) (e.g. Freeman, 1988; Howells,1999; Lundvall, 1992; Lundvall et al, 2002; Cooke et al, 2004) or rather a cognitive (sectoral, technological) context (e.g. Malerba, 2002; Carlsson and Stankiewicz, 1991; Carlsson and Jacobsson, 1994, Autio and Hameri, 1994).

Recent work by geographers attempts to relate the different spaces and scales of innovation to one another. For instance, Bunnell and Coe 
(2001) seek to "defetishize bounded regions as 'containers' of innovation” (p. 583) stressing the importance of non-local networks of innovators. They argue that "the study of 'spaces of innovation' needs to be more oriented towards exploring the linkages and interrelationships between and across these various spatial levels or scales" (Bunnell and Coe, 2001, 577). Oinas and Malecki (1999, 2002) introduced the notion of 'spatial innovation systems' which is defined as 'overlapping and interlinked national, regional and sectoral innovation systems manifested in different configurations through space'. As Lawton-Smith (2006: 33) puts it, the merit of this approach is highlighting "the co-existence of interdependent factors operating at a particular time shaping geographies of innovation." Oinas and Malecki (1999: 25) suggest that understanding the 'co-functioning of proximity versus distance effects in various sorts of innovation' remains a key challenge.

This paper attempts to explore for a newly emerging area, nanoscience and nano-technology, how cognitive, technological aspects relate to geographical factors. Much recent research on the emergence of this field points to strong regional concentration of activities in 'nano-districts' or clusters (e.g., Shapira and Youtie, 2008; Zucker and Darby, 2005). But what is the extent to which innovation activity in nanotechnology is networked within the region or across technological paths?

It is fair to state that technological patterns of a novel science \& technology discipline such as nanoscience and nanotechnology will occur to a greater or lesser extent in both a spatial-geographic and a cognitive context. In this paper we examine what context predominates the evolution of nano 
science and nanotechnology.Extant research examining various social and economic attributes of nanoscience and nanotechnology has for instance highlighted the regulatory framework (which operates in a spatial-geographic context) in which this novel technology might develop (Bowman and Hodge, 2006) while other studies explicitly elucidate the spatial patterns of nanotechnology-related knowledge assets at the regional level (Shapira and Youtie, 2006) or analyze the selection of nanoscience and technology as a key research area for a national R\&D program (Lee and Song, 2007).

Research adopting a cognitive approach to examining nanoscience and nanotechnology has been profiled in a series of studies aimed at a better characterization of this novel field in terms of publication and patenting patterns, the collaborative linkages between actors, technological opportunities that are opening up, the interaction between the science and technology realms, the technology transfer mechanisms and the interdisciplinarity of the field. (Meyer and Persson, 1998; Meyer, 2000; Libaers et al, 2006; Alencar et al, 2006). The next sections will briefly review and synthesize the intellectual antecedents to the vast and rapidly growing innovation systems literature.

\section{Theoretical Background}

\subsection{Geographically bounded Innovation Systems}

The observation that technological change is systemic in nature where firms innovate not in a vacuum but in collaboration and interdependence with other organizations has been instrumental in the development of the literature on innovations systems in general, and national and regional innovation 
systems in particular (Fagerberg, 2005; Powell and Grodal, 2005; Asheim, 2000; Howells, 1998). Lundvall and Freeman are widely credited for introducing the concept of a national system of innovation in the late 80's and which has since rapidly diffused in the academic and policy-making world as a useful analytical tool to analyse innovation processes (Edquist, 2005a, b). At the center of national innovation systems and its related alternative specifications are the concepts of innovation and system-wide learning that generate continual social and economic renewal and growth (Lundvall et al, 2002).

The boundaries of a national system of innovation coincide with the geographical borders of a sovereign country. These boundaries have important implications for the institutional arrangements within the system which are strongly determined by national policies that pertain to e.g. property rights, funding levels for research, regulatory laws and enforcement etc (Edquist and Johnson, 2000). The system is typically composed of organizational actors in both private and public sectors that perform distinct tasks and in a well-functioning system are connected to each other through formal and informal inter-organizational relationships. A clear division of knowledge production and exploitation can be observed across most national systems of innovation whereby universities and government laboratories perform mostly basic research and some applied research, private firms perform mostly applied research, and posses manufacturing and marketing capabilities needed to commercialize products and services, and finally government agencies creating, enforcing, and amending institutional arrangements. 
Innovative activity is neither evenly nor randomly distributed across spatial dimensions (for a review of innovation across space see Simmie, 2005). Perhaps most prominently, Florida (2002, 2003) argues that the distribution of talent, i.e. individuals with high levels of human capital, is an important factor in economic geography that is highly concentrated and strongly associated with high-technology industry location. Or in other words, "talented individuals with high levels of human capital are likely to locate in places that give added strength or support to their productivity and which contain other talented people with whom they can interact and learn from, thereby building on existing knowledge and/or generating new knowledge" (Lawton-Smith, 2006: 33).

Some regions seem better able to generate, capture and harness knowledge and the resulting economic benefits critical to economic development than others. Successful technology-based regional development had a transformative effect on areas such as Silicon Valley, Route 128 in Boston, Research Triangle Park, and the Cambridge area in the UK, among many other regions where high concentrations of human capital are available (Saxenian, 1994; Garnsey and Heffernan, 2005; Lawton Smith et al, 2005).

Since the early 1980's there has been a revival of interest in the region as a site of economic interaction and innovation, associated with a range of approaches all of which tried to describe dynamic agglomerations and capture, as Bunnel and Coe (2001: 575) put it, the "essence of localized clusters of activity characterized by high-industry interactions involving both tangible and intangible elements". The Regional Systems of Innovation (RSI) approach was introduced by Cooke (1992) and rose to prominence in the late 
1990's. It has clear antecedents in the NSI perspective and its elements closely resemble those of the NSI approach. However, the RSI approach suggests that the sub-national region is arguably the most appropriate scale for comprehending the dynamics of and organizing policy interventions directed towards integrated innovation systems (see overview in Bunnell and Coe, 2001: 575).

As Oinas and Malecki (2002) point out referring to Asheim and Cooke (1999), the mere presence of a range of industries in a region does not make that region a 'territorially integrated' innovation system. Rather, they argue, it is the potential relatedness between the knowledge and capabilities of firms that may trigger their engagement in innovative interaction (Oinas and van Gils 2001). Research by Harrison et al. (1996), Quigley (1998) as well as Feldman and Audretsch (1999) also indicated that 'diverse locales' - defined as those with relatively large numbers of different industries - are more important for promoting innovative firm behavior than specialised ones. Small firms are seen as the beneficiaries from regional industrial diversity because they cannot create it internally (Kelley and Helper, 1999; Oinas and Malecki, 2002). In terms of our situation this means that nanotechnology firms of the type university spin-outs, new-technology based firms, etc. might have a preference to locate in areas that are characterized by greater diversity of firms and other relevant innovation actors.

In their critical appreciation of the RIS approach, Oinas and Malecki (2002: 112) also argue that while diverse regions may be more conducive to regional innovation relative to specialized ones, diversity as 'food for innovation' may not always be locally available in the right form and thus 
needs to be complemented by interaction with more distant actors. These actors can bring in specialized expertise they gained elsewhere (from their participation in another RIS). Within regions, thus, each sector has its specific connections to extra-regional partners that enhance the innovative potential of these sectors' actors. Similarly, Bunnel and Coe (2001) point to the importance of non-local innovation networks. Translated in our context this implies that we can expect to find links between regions. In an area characterized by many or at least several paths of scientific and technological development, we might expect instances in which innovation actors may have strong non-local links. At times such links might be stronger than local connections. Such regional inter-connectivity might be facilitated by the mobility of highly qualified personnel (HQP) that usually do not operate only in local but rather national or even global labor markets (Green and McKnight, 1996). Camagni (1991: 134-141) stresses that in industries characterized by high levels of technological change and uncertainty, the beneficial impact of the local milieu has its limits and wider involvement in national and even global networks is imperative for regional actors in order to avoid an erosion in innovative capacity (ibid., pp.139). Camagni's theorizing is supported by empirical results that reveal the importance of reaching beyond the local milieu into other RISs for three reasons: (1) external innovation inputs; (2) inter-firm R\&D partnerships; and (3) access to scientific and professional human capital (Keeble et al, 1998; Keeble et al, 1999).

2.2 Innovation Systems in a Cognitive Context 
Innovation patterns differ dramatically across industrial sectors and underlying knowledge and technology paradigms in terms of the sources of innovation, the precise boundaries of the innovation process, the actors involved, and the structure and organization of innovative activities. Broad differences between industrial sectors can be traced to variations in technological regimes (Nelson and Winter, 1982). Technological regimes refer to the learning and knowledge context in which firms operate and can be decomposed into three main elements - technological opportunities available to firms and associated appropriability conditions; the degree to which technical knowledge accumulates; and the specific features of the relevant knowledge base. Technological regimes determine the evolutionary processes of variety generation and selection that shape the innovation patterns in a particular sector (Malerba and Orsenigo, 1996, 1997; Carlsson et al., 2002).

Malerba (2002: 250) defines a sectoral innovation system as a "system of innovation and production ... and the set of agents carrying out market and non-market interactions for the creation, production and sale of products." Malerba notes that a sectoral system has a knowledge base, range of inputs, key technologies, and an existing or potential customer demand for its outputs. As with other innovation system specifications, the actors in the system typically are public and private organizations that have peculiar resource and cognitive endowments and interact through processes of communication, exchange, competition, collaboration, and command. These interactions are shaped by institutions and the sectoral system undergoes 
change and transformation through co-evolutionary interplay of organizations, actors, and institutions (Malerba, 2002).

A fourth variant in the family of innovation system concepts is a technological system of innovation (TSI) which is conceptually distinct from sectoral innovation systems although in practice the delineation is blurred. Technological systems focus on general purpose technologies (GPT) with widespread applications in many industries (Bresnahan and Trajtenberg, 1996). The analysis of TSIs contributes to the understanding of the characteristics which explain the innovation process of a specific technology and its evolution in an environment of different organizations and institutions. The concept is relevant for the policy maker when creating and supporting industrial settings and policies for new emerging technologies (Research Policy editorial, 2002). Carlsson and Stankiewicz (1991) define technological systems as "a network of agents interacting in a specific technology area under a particular institutional infrastructure or a set of infrastructure and involved in the generation, diffusion, and utilization of technology." More recently, Carlsson (1997: 2) describes a TSI as "knowledge and competence networks supporting the development, diffusion and utilization of technology in established or emerging fields of economic activity."

The analysis of technological systems emphasizes the interdependence between micro units (firms, universities, research organizations) and entire sectors of the economy. The macro environment is viewed as a complex network of micro relationships - not only the simple aggregation of various micro units (see also Saviotti and Metcalfe, 1991: 8). Technological innovation systems have been employed as a conceptual lens to study innovation and 
diffusion processes of specific technologies such as factory automation (e.g. robotics), electronics and computers, biotechnology, powder technology, although the applicability of the concept can be further extended to decision support for technology policy (Carlsson and Jacobsson, 1994; Carlsson, 1997; Granberg, 1996; Momma and Sharp, 1999; Meyer, 2001a). It is not surprising that authors explore nanotechnology from a particular technological or sectoral systems perspective (e.g. Miyazaki and Islam, 2007; Meyer, 2000).

\subsection{Tension or Synthesis: Towards Spatial Innovation Systems}

While both geographic and cognitive approaches have more in common than separates them, the notions emphasize certain aspects in different ways. The definition of technological or sectoral systems is close to the definition of national or regional innovation systems. The main difference between these concepts is the system boundaries. The national system of innovation is based on national boundaries. Technological differences or distance, however, determine the boundaries of a technological system. The boundaries of a technological system may not necessarily coincide with national or regional boundaries. They can cross national (or regional) borderlines, or could be very local in nature.

A number of authors from a variety of disciplines have explored the relative differences in emphasis of the different approaches and the boundaries they have drawn. One basic yet non-trivial finding in light of the development of the four different approaches is that neither the geographically bounded nor the 'cognitive' (technological, sectoral) conceptualizations fully 
capture technological change. As Oinas and Malecki (2002: 108-109) point out:

"no innovation system is located in one place only. This is why it is not enough to focus on particular RISs in trying to understand technological change. Instead, the development of a technological system takes place via the coterminous evolution of its various components in space and time. It is supported by an interlinked set of social relations in a number of RISs of different levels of socioeconomic development, (semi-)integrated by the requirements of a technological system, resulting in a distinct spatial division of labor in that system. Technological systems are not autonomous of the place-specific RISs where they originate or are transferred because local conditions may be decisive for sustaining creative interaction in making progress in specific technologies."

Time, or the respective stage of development, is introduced to mediate the differences in emphasis between the approaches. Klepper (1996) argues that technological regimes and their associated innovation patterns change over time as industrial sectors and products progress through their lifecycle. In this sense, the concept of technological systems depends on the degree of technological development. In the early stages of the development of a technology the underlying sciences can provide the frame of the system. In later stages of technological development, however, the presence of similar economic competencies could be used to delineate different technological systems (e.g. Yli-Renko and Autio, 1997). Autio and Hameri (1994) hypothesize that the importance of the local context is likely to decrease as 
technology matures. Having said this, the authors argue that one cannot view technological systems entirely detached from their national environments, and, due to the limited transferability of technological knowledge, truly global systems are not likely to emerge.

Oinas and Malecki's (2002: 109-110) concept of spatial innovation systems appears to mediate the tension by acknowledging the importance of different configurations:

“...key issues in discussing [spatial innovation systems] are (1) the simultaneous and interdependent development of components of technological systems possibly in many places, utilizing spatial division of labor among several [regional innovation systems (RISs)] specialized in different aspects of technologies, possibly in more than one [national innovation system], and (2) the 'travels' that technologies make in space and over time as knowledge flows take place along with the progress made in the frontiers of those components. The key elements in the complex spatial innovation systems are the technological paths themselves, the RISs that participate in creating the technologies or parts of them, the actors whose interaction locally and over space ultimately brings technologies about, as well as their (proximate and more distant ) relations. [...] In sum, technologies have their specific, path-dependent time geographies: technologies emerge somewhere, in a place - or sometimes similar technological solutions are invented in more than one place simultaneously .... And the further development of those technologies may take place in a new context and in a new place, where possibly new qualities are added to them. 
Technological development is the result of the intermingling of such technological paths, overlapping in content and possibly also in space." Adopting an approach that mediates the 'tension' between the geographically and cognitively bounded perspectives seems appropriate given the technology area to be studied. Based on the review of relevant works so far one can say that in light of the early stage of nanotechnology, the links to sciences will play an important role and that diverse networks of nanotechnology actors appear likely. New and smaller businesses may tend to be located in regions with considerable diversity, which in turn might suggest that the established science hubs in Britain will be centers of major activity. Given various trajectories that are typically explored in an emergent field, such as nanotechnology (Kuusi and Meyer, 2002; Meyer and Kuusi, 2004), it would be surprising if actors would have links within a region exclusively. Non-local links may be important. The following section will explore these aspects further drawing on studies that explored nano-science and technology more specifically.

\section{The Empirical Context of Nanotechnology}

\section{1 'Nanotechnology' as an emerging yet heterogeneous technology}

Nanotechnology has been selected as the area to be studied as it is often seen as 'the emerging technology' typically associated with considerable economic potential (e.g. Miyazaki and Islam, 2007; Wood and Jones, 2003). Currently this area is viewed to be at a stage where it has become a 'going concern' with several hundred businesses worldwide claiming to operate in nanotechnology or one of its subareas (e.g. Maynard, 2006). However, it is 
still considered a novel technological area ${ }^{\mathrm{il}}$ and has not yet reached the stage when one could speak of a well-defined nanotechnology industry. There are still many different approaches as to how one can define nanotechnology (e.g. Malsch, 1997, 1999; Meyer et al., 2001a, b). Attempts to come to a generally acknowledged characterization of nanotechnology have proven futile. As a consequence, actors in the field adopt working definitions for the task at hand. One of the more broadly accepted definitions is the one proposed by the US National Science and Technology Council (2002) which also informed this study:

Research and technology development at the atomic, molecular or macromolecular levels, in the length scale of approximately $1-100$ nanometer range, to provide a fundamental understanding of phenomena and materials at the nanoscale and to create and use structures, devices and systems that have novel properties and functions because of their small and/or intermediate size. The novel and differentiating properties and functions are developed at a critical length scale of matter typically under $100 \mathrm{~nm}$. Nanotechnology research and development includes manipulation under control of the nanoscale structures and their integration into larger material components, systems and architectures. Within these larger scale assemblies, the control and construction of their structures and components remains at the nanometer scale. In some particular cases, the critical length scale for novel properties and phenomena may be under $1 \mathrm{~nm}$ (e.g., manipulation of atoms at $\sim 0.1 \mathrm{~nm}$ ) or be larger than $100 \mathrm{~nm}$ (e.g., nanoparticle reinforced polymers have the unique feature 
at $\sim 200-300 \mathrm{~nm}$ as a function of the local bridges or bonds between the nanoparticles and the polymer).

Recent research (Meyer, 2007) suggests that nanotechnology is often misconstrued as either a field of technology or an area of (broadly) converging technologies while evidence to date suggests rather that nanotechnology be considered a set of inter-related and overlapping but not necessarily merging technologies. Change in nanotechnology tends to be incremental rather than discontinuous, being the result of technological path-dependencies and lockins that are only slowly giving way to more boundary-crossing activities. Miyazaki and Islam (2007) make a similar point when they speak of the evolutionary character of innovation in nanotechnology.

This is likely to affect inter-organizational networking of firms in this area. In an earlier study, one of us (Meyer, 2000, 2001a) examined networking activities of firms exploring developments in nanotechnology in the late 1990's. At that time, networking occurred rather within the established networks of the actors' respective industries (or, in the sectoral system of innovation) rather than within a new 'nanotechnology network', with its own individual characteristics. The elements of a nanotechnology innovation system were not in place then (Meyer, 2001a). This study will explore at least to some extent whether this situation has changed. Miyazaki and Islam (2007) speak of "nanotechnology systems of innovation" when they explore the scientific development of the field focusing on the science pole.

Studies so far seem to suggest that nanotechnology is still quite a 'mixed bag' of technology stressing the diverse and multidisciplinary character and the broad range of application areas (e.g., OECD, 2007, Hullmann, 2007, 
Miyazaki and Islam, 2007, Wong et al. 2007). This might raise doubts as to how much local or regional collaboration between nanotech firms can be expected. If companies located in a geographic area happen not to belong to the same 'line' of nanotechnology, collaboration might be limited or not forthcoming at all.

Interestingly, and in spite of the recognized 'mixed bag' character of nano-science and technology, much of the social-science research still looks at it as one generic field. This applies, for instance, to a range of papers recently published in a special issue of Research Policy (Bozeman et al., 2007). Most papers in this issue are grounded in evolutionary thinking and were inspired by Kuhn's (1962) concept of the structure of scientific revolutions or the suggestion that both cognitive conditions and industrial structures respond to changes in the nature and maturity of the underlying nanotechnologies (Dosi, 1982; Anderson and Tushman, 1990; Afuah and Utterback, 1997). While some papers (e.g. Bonaccorsi and Thoma, 2007) point to different approaches, relatively few papers problematized explicitly the question whether nanotechnology is an appropriate category for analyzing developments. From an evolutionary perspective, one could also argue that nanotechnology is a rather loosely coupled set of technologies that are related to different degrees and may develop quite independently of one another (e.g. Meyer, 2007). This would reinforce the point made above about the possibly limited extent of regional networking.

3.2 Nano-Districts: Concentration and Clustering? 
Studies have shown that scientific, technological development and innovation activity is often concentrated within national and regional systems of innovation. For instance, Zitt et al. (1999) documented that there is considerable regional specialization in terms of publication and patenting performance. They identified a set of regions that was characterized by high and concurrent performances across the set of science, technology and innovation indicators utilized.

Recent research on the emergence of nanotechnology points to strong regional concentrations of $R \& D$ and innovation activity, especially the joint occurrence and concentration of patent and publication activity in nanotechnologies (e.g. Noyons et al., 2003; Heinze, 2004, 2006). Studies of developments in the US also suggest strong regional concentrations in metropolitan regions (Zucker and Darby, 2005; Shapira and Youtie, 2006). Analysts have used more and more the term 'nano-districts' to identify metropolitan areas or regions with high scientific or patenting output (e.g. Shapira and Youtie, 2008). While all studies reviewed suggest that regional concentration can be observed, the extent to which this concentration is reinforced by the emergence of local/regional nanotechnology networks is less clear.

Most recently, Zucker et al (2007) presented data that, in their view, supports the cumulative model of knowledge production. They report that regional growth of nano-publication and patenting activity is positively affected both by the size of existing regional stocks of recorded knowledge in all scientific fields and the extent to which tacit knowledge in all fields flows between institutions of different organizational types.ii 
Pointing to examples of co-location of scientific and technology actors, for instance, in Twente and Grenoble, that actively develop technology platforms in emerging nanoclusters (Robinson et al., 2007), one could argue that the tacit dimension of knowledge production in nano-science and technology appears to encourage the convergence of the cognitive and spatial perspectives on knowledge production and exploitation.

Bearing in mind that Zucker et al. (2007) found that the cumulative knowledge stock of articles in non-nanotechnological fields in a given region has a significant positive effect on the rate of production of nano-articles in that region, and a corresponding observation for patenting, one could also argue that the emergence of strong nanotechnology $R \& D$ and innovative activity is not necessarily dependent only on the 'nano-actors' in a region but more widely could be related to the broader scientific and technological attractiveness of the region. Translated in our UK context this would mean that nanotechnological activity is likely to be concentrated in areas that are characterized by a high level of scientific and technological activity in general. Having said this, Shapira and Youtie's (2008) work on US nanotechnology reminds us that also new geographic concentrations of nanotechnology research have surfaced which appear to have resulted from concentrated investments in nanotechnology R\&D into single institutions.

\subsection{Structure and Membership of Nanotechnology Networks}

Previous work also allows us to develop some suggestions as to how nanotechnology networks might be structured and what members they might have, irrespective of whether they have a predominantly technological or 
regional focus. A range of authors stress the importance of science poles within the overall nanotechnology framework. For instance, Islam and Miyazaki (2007) suggest that the science pole within the 'nanotech system of innovation' is still predominant. In their analysis of nanotechnology patenting, Bonaccorsi and Thoma (2007) found that hybrid 'author-inventor' patents are the most important contributors to knowledge production underscoring the importance of institutional complementarities (private firms and universities). Meyer (2006) reported that, depending on the country, roughly $30-40 \%$ of nanotechnology patents are related to inventors who are also active in scholarly publication. All this suggests that for an emergent area, such as nanotechnology, links with science poles can play an important role, even though one can argue that, generally speaking, the role of universities for the attractiveness from a company perspective may be overestimated (see e.g. the overview in Lawton-Smith, 2006).

With respect to networks of firms in nanotechnology, studies report that firms can have different approaches towards the field and that players differ also depending on the nanotechnology area studied. Work by Avenel and his colleagues (2007) found firms are following quite different trajectories in the development of their nano-knowledge bases. In this context the authors distinguish between two general approaches: (1) 'hybridization', defined as "as the case in which each item is related to various fields: in effect, hybridization is diversity at the level of individual items." (Avenel et al., 2007: 865); (2) 'juxtaposition', which they characterize as the collection of independent scientific and technological fields within the same knowledge 
base, e.g. either physics or chemistry. Avenel et al (2007: 869) observed differences in the use of these approaches especially with respect to firm size: "New entrants in nanotechnologies - whether high tech start-ups or firms moving into the field - are those which are integrating nanotechnologies through hybridization, while firms which are already performing research in one of the technologies which form nanotechnologies (chemistry, microelectronics, biotechnologies, etc.) develop new programs of research which focus on nanotechnology fields which are new to them. [...] Small firms, at least some of them, are achieving very significant levels of diversity through intense hybridization. Big firms, with a few exceptions, also have developed diversified nano-knowledge bases, but their use of hybridization is much more limited. The diversity of their portfolio is the result of the juxtaposition of items focused mainly on one or two established scientific/technological fields. This suggests that small firms are in a better position than big firms to exploit the opportunities created by the emergence of nanotechnologies."

Libaers et al. (2006) report rather different compositions depending on the field of nanotechnology. In their study of UK nanotechnology firms, they found that multinationals appear to be the predominant firm type in the nanomaterials, their role was less strong in the case of nano-instrumentation and devices where university spin-outs and new-technology based firms were represented more prominently.

Given the different approaches firms seem to follow and technologyrelated differences in 'industry structure', considerable variety is likely to occur 
in terms of the structure and firm membership networks in UK nanotechnology.

\section{Expectations}

This section summarizes briefly some expectations that are based on insights from the literature review on the different innovation systems and the empirical background literature on nanotechnology.

1. A review of the relevant social-science literature on nanotechnology underlined the important role of the 'science pole' within the broader nanotechnology context. This might be visible in the concentration of technological and innovation-directed activity near centers of science. Furthermore, this could suggest a prominent role for academic spinouts and similar businesses. New and smaller businesses may tend to be located in regions with considerable diversity.

2. The diversity and knowledge accumulation argument presented in the innovations systems section was reinforced by empirical work on nanotechnology that suggested regional knowledge stocks in 'nonnano' sciences and technologies affect positively output in nanoscience and technology. This would imply that that nanotechnologyrelated activity is concentrated in geographical areas that are already characterized by a high level of scientific and technological activity; or, in other words, the established science hubs in Britain are likely to be centers of major activity. This concurs with the notion that the availability of highly qualified personnel, or 'talent', is a key factor in 
economic geography and is strongly associated with the location of high-tech industry.

3. Given the multiple paths of exploration and exploitation in an emergent field, it would be surprising if actors would have links within a region exclusively. Non-local links may be important. The nanotechnologyspecific literature suggested that belonging to similar lines, or trajectories, of nanotechnology is a prerequisite for collaboration between nanotechnology firms. If these technology-specific links do not exist, collaboration might be limited or hardly forthcoming while other, non-local links are correspondingly more important. Also, in geographical areas with a larger concentration of activity, it would seem likely to find more than an individual network of nanotechnologyrelated firms that do not overlap or do so only weakly.

4. Finally, empirical research on nanotechnology firms already indicated that larger and smaller firms, incumbents and new entrants approach nanotechnology quite differently and that they may play different roles in further developing particular aspects of the field or integrating different strands of developments. There is also evidence of technology-related differences in 'industry structure'; larger firms seem to be stronger in materials-related areas of nanotechnology than instrumentation and devices. The different roles that these actors play could mean that considerable variety is to occur in terms of the structure and firm membership in UK nanotechnology-related networks. 


\section{Method \& Data}

\subsection{General Approach}

The parallel analysis of science and technology indicators has proven helpful when trying to understand the dynamics between technology and related sciences (Schmoch, 1997). This study will explore this dynamics specifically for the case of UK nanotechnology applying a multi-method approach drawing on bibliometric, patent and survey analyses.

First, we explore regional concentrations for a range of indicators: scientific publications, patenting output and firm location. In this paper, regional activity is typically explored at the NUTS-1 level. These analyses are complemented with data at the more disaggregated level of towns and cities. To study the evolution of nano- science and nanotechnology in its spatial and cognitive context we compare the relevant indicators in two distinct five-year time periods i.e. 1999-2003 and 2004-2008. This comparison is extended by firm population data that is based on an earlier study by the authors (Libaers et al., 2006) which has been recently update for the purpose of the present study.

In another step, we track collaborative activity for two different datasets. Observations are presented for co-publication and co-invention data. This analysis is complemented by an exploration of inter-organizational collaboration data that was gathered through a survey (Libaers et al., 2006). We present output data in tables and graphs; the results of the collaboration analyses are mostly presented in the form of bibliographic maps. These maps are generated through a multidimensional scaling algorithm that draws on co- 
occurrence matrices of, in our case, the main locations (regions or towns) associated with either co-publications or patents.

\subsection{Data Sources}

The analyses presented in this paper draw on publication, patent, and firm location data. The publication data is derived from a nano-science database compiled at the ECOOM ${ }^{i v}$ on the basis of data obtained from the Thomson-Reuters Web of Science. We built a publication database that contains more than 100,000 SCI indexed papers topical to the nanosciences (Glänzel et al., 2003). This database encompasses a total of 6,671 papers with UK authors published between 1992 and 2001. We updated this database for the two time periods considered in our study. Below are the numbers of publications with UK-based authors in the area of nanoscience \& nanotechnology:

- 7248 papers $1999-2003$

- 14059 papers 2004-2008

The patent data utilized is drawn from a database of nanotechnology-related US patents also compiled at ECOOM. This patent database comprises about 4,000 US patents that can be related to the area of nanotechnology. We identified the following number of US patents in nanoscience \& nanotechnology assigned to UK-based organizations:

- 131 patent 1999-2003

- 174 patents $2004-2008$

Both patent and publication databases were compiled on the basis of search strategies that evolved from consultation processes with domain experts at 
the European and national levels. Details on search strategy and data retrieval are described in Glänzel et al. (2003, 14-18). One should note an interesting observation: while there is a doubling in publication activity, patent output has increased only by a third.

The UK nano-firm database was compiled in an earlier project at SPRU/University of Sussex (Libaers et al., 2006) and contains a total of 146 firms active in nanotechnology in the 1999-2003 period ${ }^{\mathrm{v}}$ ( The corresponding number of firms for the 2004-2008 period is approximately 116).The firm database was compiled through a combination of publication, patent and other data from reports and online searches. A survey of the nanotechnologyactive firms allowed us to identify the main partners of the nanotechnology firms in the private and public research sector. The sample of firms with nanoscale product offerings very likely approaches the total population of nanofirms in the UK during that period since many sources and commercial databases had been consulted. Just over $10 \%$ of the firms had been contacted for an extensive telephone survey questionnaire and were selected from across different firm types (academic spinouts, new technology based firms, multinational corporations, and corporate spinouts) and subtechnologies (nanomaterials, nanobiodevices, nanoinstruments, nanodevices, and nanoservices).

The questionnaire was divided in three main sections that covered: (1) basic corporate data such as year of founding, number of personnel and qualified scientists and engineers, location, primary activities and market segments, annual turnover in the last 3 years, and company funding; (2) Technologies being commercialized, number of patents (co)-owned, and 
number of publications published alone, with other firms, or with universities;

(3) Collaboration linkages with other firms, universities, or foreign partners. For the purposes of this study we utilized in particular data gathered on collaborative links. Respondents were asked to name at least three key organizations they collaborated with. This was cross-referenced with data on firm-type and technological orientation.

\subsection{Data Analysis: Our mapping approach}

This study draws extensively on mapping approaches for an analysis of co-publication and patenting networks. Even though the underlying data is different, the methodological approach remains the same throughout all analyses. The mapping is based on co-occurrence analysis - a well-known approach in bibliometrics and other fields. Here, pairs of collaborators are formed at the respective level of analysis. This could be on the basis of individual authors, inventors or organizations. As we are interested in the geographical dimension, we relate co-publication, co-invention as well firm collaborative data at the level of towns or regions. For instance, let us take publication data as an example. Here co-publication pairs are formed at the level of towns. Authors based in town A and B form a pair A-B, so do authors from $C$ and $D(C-D)$, etc. There is also the case of collaboration within a town or locality. There may be two authors from town A so one could track a pair AA. Pairings of this sort may be viewed duplicates in bibliometric analysis. For the purposes of our analysis in this study, exploring within-locality pairings is of interest. Therefore, we kept rather than excluded such pairings. In some instances this may mean towns are featured prominently in maps even though 
they appear not to be (strongly) linked to any other location on the map. This is extremely unlikely to happen in co-publication maps where the output and consequently the number of links are much higher than in e.g. patents. In the patent context, this situation may occur in the case of large public or corporate $R \& D$ laboratories that are located in a town/county without university or other research infrastructure.

After establishing pairings, co-occurrence matrices were generated drawing on the Bibexcel bibliometric freeware programme (Persson, 2008). The matrices included integer counts of co-occurrence frequencies between two locations and were imported into a multidimensional scaling (MDS) program for the creation of two-dimensional maps. More specifically, we applied the SYSTAT routine to these matrices to generate maps. We followed the process described by Persson (1994). A detailed step-by-step description is available online. ${ }^{\text {vi }}$ The approach chosen has been adopted in a number of studies in bibliometric analysis of scholarly communication. ${ }^{\text {vii }}$ The maps offer a heuristic perspective on how localities are related to each other through coauthorship in nano-science publication, co-invention and co-classification (technological distance) in nano-patenting. The closer two nodes (here towns or regions) are to each other the more they are related to each other by cooccurring links. The strength of the links is indicated through the thickness of the lines between them. The size of circles associated with localities indicate the level of activity (e.g., publication or patent outputs). ${ }^{\text {vii }}$ Viewing the maps should help clarify how localities are related to each other by collaboration or through cognitive links. While it is difficult to judge or estimate exactly the respective strength of local vs regional, national or international links on the 
basis of the presented maps, a visual inspection should nevertheless offer a strong impression of how localities are linked.

The mapping routine does not allow an unlimited number of nodes to be included. Only up to 70 nodes can be accommodated by the maps. Often analysts reduce the number of nodes for the benefit of greater clarity. This implies that a threshold has to be set and localities on one (e.g. the science) map would not necessarily appear on another (e.g. patent) map. While this is a limitation, the chosen approach nevertheless offers an overview of the overall structure and pattern in collaboration. The approach focuses attention on the key players in a field and how they are related to another. Strong variation between maps would suggest that there are substantial differences in collaborations between locations. Differences between publication and patent-based maps would indicate that technical collaboration does not necessarily follow the patterns of scientific cooperation, or vice versa.

For patent data we are able to compare networks of inventive collaboration with cognitive networks that relate locations to each other in terms of technological proximity or distance. This comparison draws on patent classification data. We have drawn on the International (IPC) and US patent classification schemes and linked locations with all patent classes (at the 6digit IPC level or equivalent) that were associated with patents that included local residents as inventors. A considerable overlap between network maps would suggest that technological and collaborative links coincide. Our analysis of how co-publication and co-patenting activities are linked in space is driven exclusively by bibliometric maps generated by the BibExcel algorithm. While the same analysis can be performed using statistical analysis 
(e.g. Pearson correlations), the algorithm implicitly performs these statistical computations and graphically displays them to facilitate visual comprehension.

\section{Findings}

This section is divided into two main parts. First the regional distribution of publication, patenting and firms is explored. This analysis is then followed by an analysis of collaborative patterns. In the first section, we report on observations that seem to point to strong regional concentration. This finding is not surprising and in line with expectations. In the second section on collaborative activity, we find a less straightforward situation which seems to suggest in particular that networking of firms is neither limited nor particularly focused on the region in which they are located.

\subsection{Regional Distribution}

First data is presented on publication output, then regional distributions on patenting and firm location are introduced. Our overall finding confirms initial expectations. In the case of publication, patent and firm location data we can establish concentration of activity on a small number of UK regions whereas the remainder of activity is spread sparsely across the remainder of the UK. Publication activity is concentrated on the South-East, the East of England, and the Greater London region (as Fig. 1 illustrates). Almost half of all the UK's publication activity in nanotechnology in both five-year time periods is concentrated in these three regions which encompass most of the country's leading universities.

A similar situation can be observed when exploring patenting data. Patenting activity converges again on the South-East, the East of England, 
and the Northwest, closely followed by the Greater London area (Fig. 2). Here regions were ranked on the basis of the number of patent assignees based in those regions. The Southeast strengthened its leadership position in patenting in the second five-year time period whereas the North West and the West Midlands witnessed a significant drop in patenting activity in the same time period relative to the first time period. Again, we observe a concentration of high patenting activity in areas with a strong scientific base.

Fig.3 depicts the distribution of nanotechnology-based firms across the NUTS1 UK regions. Regions with notably high concentrations of nanofirms are the Southeast, East England and to a lesser extent Northwest England. A comparison across the two time periods indicates that the Southeast, the Greater London area, the Northwest and East Midlands improved their relative position whereas the Southwest and Wales lost ground. The distribution on nanofirms appears to a certain extent mirror the regional distribution of nanopatenting activity in Fig. 2. Our survey of nanofirms further indicates that Headquarter offices (in particular of large corporations involved in nanotechnology) are often based in and around London whereas smaller nanotechnology firms (NTBFs, academic spinouts) are, for instance, concentrated in the East Anglia region around Cambridge or in the South East (especially around Oxford). More specifically and considering all three output indicators concurrently, we note that nano-scale science and technology outputs seem to be related to each other and to nano-firms. Typically regions with strengths in nano-papers and nano-patents account for similar shares in nano-firms. As such, this finding is not unexpected considering earlier work (e.g. Shapira and Youtie, 2008, Zitt et al., 1998) and is consistent with our 
initial expectations. In a sense the loci of nanotechnology exploitation are often co-located with the loci of nanoscience exploration highlighting the importance of science poles.

Fig. 4 provides a comparative analysis across a ten-year time period of publication, patenting, and exploitation activity in the various NUTS 1-level UK regions. It confirms the extraordinary role of just three regions (Southeast, Greater London, and East England) in shaping the UK's prominent nanoscience \& technology profile. Exploration and exploitation of this emerging technology is heavily concentrated in three to four regions. The observation of parallel strengths (and correspondingly also weaknesses) in science, technology, and firm activity in the various regions raises questions about the extent to which it is possible to trace collaborative links within the regions or between neighboring regions. Here the literature around spatial innovation systems suggested that we might find a more ambiguous situation rather than closed nano-clusters. Both regional and non-local links of actors will play a role. The existence of strong intra-or extra regional collaborations will be explored in the next section of our analysis. 


$$
\begin{aligned}
& \text { <insert Fig. } 1 \text { about here>> } \\
& \text { <<insert Fig. } 2 \text { about here>> } \\
& \text { <<insert Fig } 3 . \text { About here>> } \\
& \text { <insert Fig } 4 \text { about here>> }
\end{aligned}
$$

\subsection{Collaboration within Regional or Technological Context?}

This section explores the extent of local and regional collaboration in terms of science and technology as well as the inter-organizational collaboration of nanotechnology firms. The maps of scientific and technological collaboration offer mixed results, pointing to links that are based on geographical proximity as well as links to locales comparatively far removed in geographical terms. This is in line with expectations. Our analysis of nanotech firms' collaborative activity points to collaborative groupings that could be explained on the basis of technological proximity rather than regional aspects. We can also identify substantial diversity in regions with larger activity. As expected, these networks do not necessarily overlap at the level of nanotechnology firms.

\subsubsection{Co-Publications}

The co-publication analysis offers a mixed picture that suggests strong international collaboration in nanosciences linking science hubs in the UK to key overseas centres of scientific activity. The maps in Fig 5 offer an overview of collaborative linkages between different entities at the town/city level. A total of 16,511 (1999-2003) and 46,932 (2004-08) addresses could be identified indicating a very strong growth in the number of both publications and actors between the two time periods as can be seen from the much denser network in the upper map as compared to the one in lower map. The 
closer places are located to one another on a map the stronger the collaborative link between them. Circle size serves as an estimate for the publication output in the different locations.

One can observe a number of links between cities and towns that are located relatively closely to another in Fig. 5. For instance, there are comparatively strong links between London and Oxford, Oxford and Cambridge, and Guildford and Brighton. Having said this, there are also examples suggesting the opposite. To illustrate, Glasgow is more closely linked to Cambridge than it is to St Andrews which is geographically closely located to Glasgow. Researchers in Manchester appear to collaborate more intensively with their colleagues in Oxford or London rather than with researchers in Sheffield or Nottingham who are geographically much closer. A similar set of patterns can be observed for the more recent period. Both maps illustrate the strong links of UK researchers with peers in other countries. In terms of collaborative activity, London appears closer to Tsukuba, Moscow or Stuttgart in 1999-2003 than it is to Cambridge. A similar picture can be observed for 2004-2008 where foreign cities, such as Singapore, Shanghai, Toronto, Madrid, and, again, Tsukuba lie between the capital and the university town. On the other hand, one can still trace very regional collaborations. The link between Bristol and Didcot, extended by Bath (19992003) and Cardiff (2004-2008) respectively, is an example.

Figure 6 provides a much clearer picture of domestic collaborative linkages between UK regions at the NUTS 1-level. The thickness of the links is a measure of the intensity of collaboration. A visual inspection of Fig. 6 indicates that one can find evidence for links between neighboring regions 
(e.g., East England and London, or South-East and South-West). However, the map also indicates that the South-East is closer to Yorkshire and The Humber than London in terms of nanotechnology co-publications. A comparison for the two periods indicates that there are changes in emphasis and intensity but the overall collaborative relationships at the regional level are stable.

The maps illustrate for the area of nano-science cooperation that nonlocal links play a vital role in scientific collaboration. However, they also show that there is an element of geographical proximity at play. Both observations are in line with expectations that suggested regional concentrations with important non-local links.

$$
\begin{aligned}
& \text { <<insert Fig } 5 \text { about here>> } \\
& <<\text { insert Fig. } 6 \text { about here>> }
\end{aligned}
$$

\subsubsection{Co-Inventions}

We know from other studies that scholarly collaboration is considerably more frequent than technical collaboration which is often exclusively in-house (e.g. Meyer and Bhattacharya, 2004). As reported, the overall number of patents tracked for the UK in nanotechnology was comparatively small in both time periods. Hardly any co-assignations (i.e., co-ownership) between firms or other organizations could be traced ( 3\%). We traced 254 addresses for 162 UK-based inventors; a total of 68 patents listed more than one inventor. Figure 7 presents an overview of collaborations that could be traced at the level of inventor locations. In light of the low overall level of inventive collaborative activity we need to be careful in interpreting the data, especially since there is very little inter-firm activity to be tracked. 
Comparing these maps with those for UK nano-science collaboration suggests that there are different patterns underlying patenting and publication in nanoscience and technology. Research elsewhere indicated that only a very small fraction of nano-scientists actually engage in patentable inventive activity (e.g. Meyer 2006). In the UK, approximately $0.6 \%$ of active nanoscientists are also involved in nanotechnology patenting (Meyer 2006, 2007). ${ }^{\text {ix }}$ This means that even if these links reflected also scientific collaboration, they would 'disappear' among the much larger numbers of purely scientific collaborations.

Having said this, the share of nano-scientists among inventors is quite high, especially in the UK: we found that around $40 \%$ of all nanotechnology inventors were also active in scientific publication. ${ }^{x}$ Bearing this in mind, it is perhaps less surprising to find the main science centers of the UK feature somewhat prominently in terms of co-patenting. Moreover, co-patenting activity in the first time period is significantly more fragmented than in the second time period. Another observation is that co-patenting is frequently an international endeavor.

Figure Error! Main Document Only. visualizes co-invention patterns in terms of technological distance in the two time periods considered. Technological distance, or proximity, between two places is determined on the basis of the patent classifications (at the IPC 6-digit level) they share. ${ }^{\mathrm{xi}}$ The closer towns or counties are on the map, the more similar they are in (cognitive) terms of co-classifications. The thickness of the lines indicates the intensity of shared co-classification links. The map for the period 1999-2003 points to relatively few cognitive links between towns whereas the 2004-2008 
map shows a significant increase in links. In this sense we observe a shift from a fragmented, disjointed pattern to a more extensive, dense pattern of links. To some extent the relatively few links we observed in the earlier period could be seen to reflect collaborative activity between inventors in different locations. We tracked very specific links, mostly only between two or few more locations. One case in point is Bath which is linked to Glenham and Amenia in the US in both co-classification and co-patenting maps. There are other examples (Reading-London, or Southampton-Baton Rouge). Here, only a small group of people work in different locations on very specific technological topics. Also there appear to be relatively few co-classification links between places that are not already linked through strong collaborative activity. Where these links occur, one often finds connections between UK and overseas localities lending support to the notion of the importance of nonlocal links along technological paths.

There is a substantive change in the later period (2004-2008). Here the cognitive network map is considerably more integrated. While dyadic links remained strong in the earlier map, the later map points to the emergence of cognitive networks. This is reflected also in the co-patenting data where localities are linked to a larger extent in the second period (cf. Figure 7). One could argue that in this sense exploitation of nanotechnology conforms with a technological systems paradigm. The more cognitive links are established between locations the greater the potential for engagement between actors in the related locations. Such a strategy may yield more radical innovations that require the combination of more disparate technological knowledge not necessarily available at the regional or even national level. This potential has 
not been realized as there are still fewer co-patenting links than there are coclassification links. The maps illustrate that there are important cognitive links both with geographically close and distant localities. An example for relatively close links are Cambridge and London which are linked to Watford, Oxford, Farnborough, Surrey, or Middlesex while at the same time connections exist between these and, e.g., Tblisi or Moscow.

$<<$ insert Fig. 7 about here >>

$<<$ insert Fig 8 about here>>

Figure Error! Main Document Only. also points to locations at the fringe of a network which, by definition, do not assume a central position in the network and are out of sight of the dominant players which allows these actors to deviate from 'industry recipes' (Spender, 1989) and experiment with technologically distant partners that can result in radical innovations, a result which is consistent with prior research (Gilsing et al, 2008). Other salient features of local or more distant collaborative inventive activity at the town/city level can be gleaned from Tables $1 \& 2$ which illustrate the occurrences of local and distant (non-local) collaborative linkages by town for both time periods under study. These tables suggest that co-inventive collaborations in the large UK science poles are primarily non-local in line with our expectations. Other locations with high overall levels of collaboration in the first time period indicate a substantial amount of local co-inventive activity. However, in the most recent five-year time period towns outside the UK large science poles (Oxford, Cambridge and Greater London) see a significant increase in non-local co-inventive activity. Both tables suggest how important non-local collaborative linkages are for local clusters. 


\section{<<insert Table 1about here>> \\ $<<$ insert Table 2 about here >>}

Table 3 illustrates the breadth of technology development at the town level. In the first time period well-established and large science poles/clusters appear to develop a broad range of technologies with the exception of Oxford that in the second time period catches up significantly in terms of breadth of technology development. Compared to the first time period, all large and small 'nano-clusters' expand the breadth of technology development in the second time period, with the exception of Manchester that seems to develop more depth in a narrower range of technologies i.e. specializes in fewer technologies.

\section{$<<$ insert Table 3 about here>>}

\subsubsection{Collaborative Ties of Nano-related Companies}

An analysis of collaborative ties of the 146 UK nanotechnology firms in the time period from 1999 to 2003 allowed us to develop a better understanding of firms' inter-organizational networking activity. Our network analysis is based on a survey in which firms were asked to name their main collaborators, irrespectively whether the partner was a public or private organization. These nominations enabled us to analyze pairs of collaborators. At times, this allowed us to identify broad collaborative networks of nanotech firms. Our approach allowed us also to distinguish between dedicated nanotechnology firms (from our initial database) and the (not necessarily nanotechnology-focused) organizations they nominated. Some firms partnered also considerably with non-nano/non-UK organizations. The pairs of 
collaborators allowed us to carry out cluster analysis which identified a total of 15 clusters. xii $^{\text {in }}$

These clusters and their membership were inspected manually to determine the respective technological orientation and regional base. Most clusters have a mixed membership of participants from industry and university. Only one exclusive firm cluster (\#11) can be identified. We identified 6 mixed clusters with a dominance of firm partners and 8 mixed groupings with a more balanced distribution of participants. We found often very small clusters of $5-10$ organizations around 1 or 2 firms. There are also larger clusters with around 15 or more members and at least 5 dedicated nanotechnology members. Table 4 presents a summary of the data, specifying the cluster size, the number of pure nanotechnology-focused firms, UK-based firms, the number and share of university partners, and the general technological focus of the cluster. Figure 9 offers an overview of how the clusters are structured in terms of UK regions. Figure 10 summarises the composition of cluster members by firm type.

\section{<<insert Table 4 about here>>}

There is considerable diversity amongst the clusters in terms of regional and technological orientation as well as firm membership. Only five small clusters with five members or less are based in one region. The other ten clusters with up to 55 members are characterized by a considerable variety of the regions its member firms belong to, underlining the importance of non-local links. While it is possible to identify a relative concentration of nanotech firms on a region within larger clusters, the share of a single region seems not to exceed one-third (with one notable exception). 
<<insert Fig 9 about here>>

$<<$ insert Fig 10 about here>>

Another interesting observation relates to clusters within regions that account for a substantial number of nanotech firms. We found that firms within a region appear not to form a large regional nanotech cluster. Instead, groupings of 3-5 firms were identified that belong to three or more (interregional) clusters that can be defined along technological characteristics (see Table 4). To illustrate, the East of England region can point to more than 15 nanotechnology firms - five belong to a network of materials-oriented device producers (cluster 2); another five are electronics-related ventures (cluster 4); and a third group is nanomaterials-oriented (cluster 6). Perhaps, only in the case of cluster 4 , one could say that firms from one region are dominant. The South East is the region that accounts for more nanotech firms than any other region in the UK (around 20). However, looking at clusters with more than 5 nanotech firm members, there is no cluster in which its share reaches beyond one-third. This observation is in line with expectations. Both innovation systems literature and earlier empirical work on nanotechnology suggested that there might be considerable non-local links of actors within regions and that there might be knowledge exchange along technological lines.

The clusters are also diverse if one examines them by firm type (see Fig. 10). Most larger clusters seem to have a broad range of firm types involved, including multinational corporations (MNCs), spin-outs, or newtechnology based firms (NTBFs) which do not qualify as university, other public or corporate spin-out. MNCs are involved in 7 of the 15 clusters; NTBFs and university spin-outs are engaged in 10 clusters, respectively. Only in one 
cluster (\#9) the involved nanotechnology-focused firms are exclusively multinationals. The high number of university and other public research spinouts seems to confirm our initial expectation that the science pole plays an important role in the commercialization of nanotechnology. Also, the diversity of firms may point to a certain division of labor between large corporations and small new businesses.

Due to data limitations a similar analysis could not be conducted for nanofirms in the 2004-2008 time period. We found earlier through co-patent and co-classification analysis that local innovation activity has increased overall in technological breadth. This implies that the potential for overlap between different local nanotech networks has also increased. At the same time there are more inter-local links both in cognitive and collaborative terms. This would suggest that that there is also increased potential to collaborate along non-local technological lines. Both developments may result in some integration. While it is difficult to establish a trend, we observed still considerable variation between localities in terms of the level of local collaborative activity. The trend towards increased breadth in patenting of towns and counties appears more consistent. Towns with a higher patent breadth seem to have a more central position in non-local collaborative networks.

\section{Discussion and Conclusion}

This contribution sought to explore the question whether new, sciencerelated technologies, such as nanotechnology, follow a more regional or a more cognitively determined pattern of emergence. This section summarises and discusses the key findings of our study with respect to the four broad 
research issues we identified earlier before making a few suggestions for further research.

\subsection{Importance of the 'Science Pole'}

Our findings confirm the importance of the 'science pole' in the nanotechnology framework. This has become clear in a number of ways: (1) the relative importance of university spin-outs and other public researchrelated start-ups in most of the clusters studied (2) the fact that there were hardly any clusters of firms that did not include a university or public research institute, (3) the network maps and cluster data have shown that there is a tendency of firms and non-scientific activity to concentrate around the established science hubs. In that sense, our observations concur with the findings by Zucker et al. (2007).

\subsection{Diversity and Knowledge Accumulation: Predominance of 'Science Hubs'}

We found that there is indeed considerable regional concentration of nanotechnology activities in terms of science, technology and firm location. Typically regions strong in one of the activities are strong in the other two as well. This corresponds to work by others (e.g. Zitt et al., 1999; Zucker et al., 2007). We identified strengths for regions, such as the South-East, the East of England, London, and to a lesser extent the Northwest all of which are strong in science, technology, and innovation activity across the board and not just in nanotechnology. 
Comparing our observations with US studies, we can observe similarities in so far that we also find strong concentrations of explorative and exploitative activity in regional or metropolitan centers (Zucker and Darby, 2005; Youtie and Shapira, 2006 and 2008). Having said this, regional concentration does not preclude strong, non-local networks from emerging along technological lines.

\subsection{Importance of Technology-Specific, Non-Local Links}

The spatial innovation systems approach by Oinas and Malecki (2002) tries to build a bridge between the regional and technological systems approaches suggesting that a given RIS may require specialized (also technological) expertise from another RIS and thereby connecting locales to the 'travels' technologies make over space and time. Indeed, our findings seem to suggest that the concentration on regions, does not necessarily reflect the nature of the collaborative networks of the firms in the industry. Here, we found evidence of strong, non-local inter-firm links that could be associated with clusters related to nanomaterials, nanodevices, nanoinstrumentation, or nano-electronics. Correspondingly, we observed that in regional centers with large concentrations of nanotech activity, firms belonged to different networks or clusters rather than a large local/regional collaborative network. In that sense our study offers an extension to other work that identifies concentrations and speaks of clusters or nano-districts, which might be misunderstood as suggesting highly territorially integrated networks. Our research should have clarified that considerable regional concentration of 
activities can co-exist with dispersed technology-focused, predominantly nonlocal networks or clusters.

\subsection{Diversity in 'Industry Structure'}

Earlier research suggested that the role in exploring and integrating various aspects of nanotechnology differs considerably between firms, especially between firms of different size. Similarly, the 'industry structure' the relative importance of different firm types - varied depending on the specific nanotechnology area in question. Our observations also point to a variety of firm types within most networks. MNCs and spin-outs appear to complement each other in the clusters we identified.

\subsection{Future research}

One issue for future research is the way in which the nanotechnology firms are embedded in their respective region. Evidence presented in this paper pointed to the attractiveness of regions around science hubs, such as Cambridge, Oxford, or London, and how nanotechnology firms really link up to a larger nanotechnology group locally and further away. Arguably, links to other innovation-relevant actors outside the nanotechnology sphere may play a role. This could include highly specialized service providers in the knowledge-intensive business services area. One could contend that support structures and services play a particularly important role in certain regions that may help explain regional concentrations of science and technology activity. These kinds of links deserve to be explored further. 
The notion of converging technologies has been popular in policy circles, implying that nanotechnology is at the center of a broad-brushed integration of biotechnology, cognitive and information technologies. If that was indeed to happen, one should be able to trace indications of such developments in hub regions that attract 'talent' (e.g., the East and the SouthEast). Here analysts should be able to witness then the integration of at least some of the networks.

The interplay between new entrants and incumbents, large and small firms is under-explored in this technology area and clearly deserves further attention. Our evidence could just underline that there seem to be differences in 'industry structure' and an emerging division of labor between small and larger firms in the field. 


\section{References}

Afuah, A. and Utterback J.M. (1997) Responding to structural industry changes: a technological evolution perspective, Industrial and Corporate Change, 6, 183-202.

Alencar, M., Antunes A., and Porter, A. (2006) Nanopatenting raise issue for managers and countries, Research -Technology Management, 49, 8-

9.

Anderson, P. and Tushman ML. (1990) Technological discontinuities and dominant designs: a cyclical model of technological change, Administrative Science Quarterly, 35, 604-633.

Asheim, B. T. (2000) Industrial Districts: The Contributions of Marshall and Beyond, in Clark, G., Feldman, M., and Gertler, M. (Eds.) The Oxford Handbook of Economic Geography. Oxford University Press. New York

Asheim, B.T.and Cooke, P. (1999) Local learning and interactive innovation networks in a global economy, in P. Oinas and E.J. Malecki (Eds.), Making Connections: Technological Learning and Regional Economic Change. Ashgate: Aldershot, 145-178.

Autio, E and Hameri, A-P. (1994) Technological systems: structures, dynamism, and sources of change, Espoo: Helsinki University of Technology, Institute of Industrial Management. Working Papers $1994 \mid 1$. 
Avenel, E., Favier, A., Maa, S., Mangematin, V.and Rieu, C. (2007) Diversification and hybridization in firm knowledge bases in nanotechnologies, Research Policy, 36, 864-870.

Bibexcel, bibliometric analysis freeware developed by Prof. Olle Persson. Downloadable from www.umu.se/inforsk.

Bonaccorsi A. and Thoma G. (2007) Institutional complementarity and inventive performance in nano science and technology, Research Policy, 36, 813-831.

Bowman, D.M. and Hodge, G.A (2006) Nanotechnology: Mapping the wild regulatory frontier, Futures, 38, 1060-1073.

Bozeman, B., Laredo, P., Mangematin, V. (2007) Understanding the emergence and deployment of "nano" S\&T, Research Policy, 36, 807812.

Bresnahan, T. F., and M. Trajtenberg (1996) General purpose technologies: 'engines of growth'?, Journal of Econometrics, 65, 83-108.

Bunnell, T. G. and Coe, N. M. (2001) Spaces and scales of innovation, Progress in Human Geography 25, 569-589.

Camagni, R. (1991) Local 'milieu', uncertainty and innovation networks: towards a new dynamic theory of economic space, in Camagni, R. (Ed.) Innovation Networks: Spatial Perspectives, pp. 121-42. Belhaven. London

Carlsson, B. (Ed.) (1997) Technological Systems and Industrial Dynamics. Kluwer Academic Publishers Boston, Dordrecht

Carlsson, B. and Jacobsson, S. (1997) Diversity creation and technological systems: a technology policy perspective, in Edquist, C. (Ed.). 
Systems of Innovation: Technologies, Institutions and Organisations. Pinter. London

Carlsson, B., and Jacobsson, S.(1994) Technological systems and economic policy: the diffusion of factory automation in Sweden, Research Policy, 23, 235-248.

Carlsson, B., et al. (2002) Innovation Systems: Analytical and Methodological Issues, Research Policy, 31, 233-245.

Carlsson, B. and Stankiewicz, R. (1991) On the nature, function, and composition of technological systems, Journal of Evolutionary Economics, 1, 93-118.

Cooke, P. (1992) Regional innovation systems: competitive regulation in the new Europe, Geoforum, 23, 365-382.

Cooke, P., Heidenreich, M., and Braczyck, H.J. (2004) Regional Innovation Systems: The Role of Governance in a Globalized World. $2^{\text {nd }}$ ed. Routledge. London, New York

Dosi, G. (1982) Technological paradigms and technological trajectories - A suggested interpretation of the determinants and directions of technical change, Research Policy, 11, 147-162.

Editorial (2002) Research Policy, 31, 185-190.

Edquist, C. (2005a) Systems of Innovation Approaches - Their Emergence and Characteristics, in C. Edquist (Ed.) Systems of Innovation: Technologies, Institutions and Organizations, Washington: Pinter. Edquist, C. (2005b) Systems of Innovation: Perspectives and Challenges, in J. Fagerberg, D. Mowery and R. Nelson (Eds.) The Oxford Handbook of Innovation, Oxford University Press: New York 
Edquist, C., and Johnson, B. (2000) Institutions and Organizations in Systems of Innovation, in Edquist, C., and McKelvey, M. (Eds.) Systems of Innovation: Growth Competitiveness and Employment. Edward Elgar: Cheltenham.

Fagerberg, J. (2005) Innovation: A Guide to the Literature, in J. Fagerberg, D. Mowery and R. Nelson (Eds.), The Oxford Handbook of Innovation, eds. Oxford University Press: New York.

Feldman, M.P.and Audretsch, D.B. (1999) Innovation in cities: science-based diversity, specialization and localized competition, European Economic Review, 43, 409-429.

Florida, R. (2002) The Rise of the Creative Class. Basic Books: New York. Florida, R. (2003) People, Place, and Region: The Economic Geography of Talent, Annals of the Association of American Geographers, 92, 743 $-755$.

Freeman, C. (1987) Technology Policy and Economic Performance: Lessons from Japan. London: Pinter.

Freeman, C. (1988) Japan: a New National System of Innovation?, in G. Dosi (Ed.) Technical change and economic theory, ed., London: Pinter Publishers.

Garnsey, E. and Heffernan, H. (2005) High-technology clustering through spin-out and attraction: The Cambridge Case, Regional Studies, 39, 1127-1144.

Gilsing, V., Nooteboom, B., Vanhaverbeke, W., Duysters, G., and A. Van den Oord. (2008) Network embeddednes and the exploration of novel 
technologies: Technological distance, betweenness centrality and density, Research Policy, 37, 1717-1731.

Glänzel, W., Meyer, M., Du Plessis, M., Thijs, B., Magerman, T., Schlemmer, B., Debackere, K., Veugelers, R. (2003) Nanotechnology: Analysis of an emerging domain of scientific and technological endeavour.' Steunpunt O\&O Statistieken: K.U.Leuven.

Granberg, A. (1996) On the pursuit of systemic technology policies in an unstable environment: reflections on a Swedish case, Research Evaluation, 6, 143-157.

Green, A. and McKnight A. (1996) The changing distribution and composition of the highly qualified, unpublished conference paper, Institute for Employment Research, University of Warwick

Harrison, B., Kelley, M.R., Gant, J. (1996) Innovative firm behaviour and local milieu: exploring the intersection of agglomeration, firm effects, and technological change. Economic Geography, 72, 233-258.

Heinze, T. (2004) Nanoscience and nanotechnology in Europe: Analysis of publications and patent applications including comparisons with the United States, Nanotechnology Law \& Business, 1, 427-447.

Heinze, T. (2006) Die Kopplung von Wissenschaft und Wirtschaft. Das Beispiel der Nanotechnologie, Frankfurt/New York: Campus.

Howells, J. (1999) Regional Innovation Systems, in Archibugi, D., Howells, J. and Michie, J. (Eds). Innovation Policy in a Global Economy. Cambridge: Cambridge University Press

Keeble, D., Lawson C, Lawton Smith, H., Moore, B., and F. Wilkinson (1998) Internationalisation processes, networking and local embeddedness 
in technology-intensive small firms, Small Business Economics, 11, $327-42$.

Keeble, D., Lawson C, Moore, B, and F. Wilkinson (1999) Collective Learning processes, Networking and 'Institutional Thickness' in the Cambridge region, Regional Studies, 33, 319-332.

Kelley, M.R. and Helper, S (1999) Firm size and capabilities, regional agglomeration, and the adoption of new technology, Economics of Innovation and New technology, 8, 79-103.

Klepper, S. (1996) Entry, Exit, Growth and Innovation over the Product Life Cycle, American Economic Review, 86, 562-83.

Kuhn, T.S. (1962) The Structure of Scientific Revolutions. University of Chicago Press: Chicago.

Kuusi, O., Meyer, M. (2002) Technological generalizations and leitbilder - the anticipation of technological opportunities, Technological Forecasting and Social Change, 69, 625-639.

Lawton Smith, H, Glasson, J, and Chadwick, A . (2005) The geography of talent: entrepreneurship and local economic development in Oxfordshire, Entrepreneurship and Regional Development, 17, 449476.

Lawton-Smith, H (2006) Universities, Innovation and the Economy. Routledge: Abingdon, New York.

Lee, Y.G. and Song, YI. (2007) Selecting the key research areas in the nanotechnology field using technology cluster analysis: A case study based on national R\&D programs in South Korea, Technovation, 27, 57-64. 
Leydesdorff, L. (2008) On the normalization and visualization of author cocitation data, Journal of the American Society for Information Science and Technology, 59, 77-85.

Libaers, D., Meyer, M., and Geuna, A. (2006) The role of University Spinout Companies in an Emerging technology: The case of Nanotechnology, Journal of Technology Transfer, 31, 443-450.

Lundvall, B. et al. (2002) National Systems of Production, Innovation and Competence Building, Research Policy, 31, 213-231.

Lundvall, B.A. (Ed.) (1992) National Systems of Innovation: Towards a Theory of Innovation and Interactive Learning. London: Pinter

Mahdi, S.and K. Pavitt (1997) Key national factors in the emergence of computational chemistry firms, International Journal of Innovation Management, 1, 355-386.

Malerba, F. (2002) Sectoral systems of innovation and production, Research Policy, 31, 247-264.

Malerba, F. (2005) Sectoral Systems: How and Why Innovation Differs Across Sectors, in J. Fagerberg, D. Mowery and R. Nelson (Eds.) Oxford Handbook of Innovation, New York: Oxford University Press.

Malerba, F., and Orsenigo, L. (1996) Schumpeterian patterns of innovation. Cambridge Journal of Economics, 19, 47-65.

Malerba, F., and Orsenigo, L. (1997) Technological regimes and Sectoral patterns of innovative activities, Industrial and Corporate Change, 6, 83-117. 
Malsch, I. (1997) Nanotechnology in Europe: Experts' perceptions and scientific relations between sub-areas, Institute for Prospective technological Studies (IPTS-JRC): Seville.

Malsch, I. (1999) Nanotechnology in Europe: scientific and organizational dynamics, Nanotechnology, 10, 1-7.

Maynard, A. (2006) Nanotechnology: A Research Strategy for Adressing Risk. Project on Emerging Technologies. Woodrow Wilson International Center for Scholars.

Meyer, M. (2000) Hurdles on the way to growth, HUT-ISIB Working paper Series, 2000/1, Helsinki University of Technology: Espoo.

Meyer, M. (2001a) Between Technology and Science, Exploring an Emerging Field, D. Phil. Diss., Brighton, University of Sussex.

Meyer, M. (2001b) Patent citation analysis in a novel field of technology: An exploration of nano-science and nano-technology, Scientometrics, 51, 163-183.

Meyer, M. (2006) Are patenting scientists the better scholars? An exploratory comparison of inventor-authors with their non-inventing peers in nanoscience and technology, Research Policy, 35, 1646-1662.

Meyer, M. (2007) What do we know about innovation in nanotechnology? Some propositions about an emerging field between hype and pathdependency, Scientometrics, 70, 779-810.

Meyer, M., Kuusi, O. (2004) Nanotechnology: Generalizations in an interdisciplinary field of science and technology, Hyle, 10, 155-170. 
Meyer, M., and Persson, O. (1998) Nanotechnology - Interdisciplinarity, patterns of collaboration and differences in application, Scientometrics, 42, 195-205.

Miyazaki, K., and Islam, N. (2007) Nanotechnology systems of innovation an analysis of industry and academic research activities, Technovation, 27, 661-675.

Momma, S. and Sharp, M. (1999) Developments in New Biotechnology Firms in Germany, Technovation, 19, 267-282.

Nelson, R., and Winter, S. (1982) An Evolutionary Theory of Economic Change. Cambridge, MA. Belknapp Press

Nelson, R.R. (ed.) (1993), National Innovation Systems: A Comparative Analysis. Oxford University Press: New York, Oxford.

Noyons, E. C. M., Buter, R., Raan, A. F. J. V., Schmoch, U., Heinze, T., Hinze, S., Rangnow, R. (2003), Mapping Excellence in Science and Technology across Europe. Nanoscience and Nanotechnology, Report to the European Commission: University of Leiden.

Oinas, P. and Malecki, E.J. (2002) The Evolution of Technologies in Time and Space, International Regional Science Review, 25, 102-131.

Oinas, P. and Malecki, E.J. (1999) Spatial innovation systems, in P. Oinas and E.J. Malecki (Eds.), Making Connections: Technological Learning and Regional Economic Change. Ashgate: Aldershot, pp. 7-33.

Oinas, P. and van Gils, H. (2001) Identifying contexts of learning in firms and regions, in D Felsenstein and M Taylor (Eds.) Promoting Local Growth: Process, Practice, Policy. Ashgate: Aldershot. 
Persson, O. (1994) The intellectual base and research fronts of JASIS 19861990, Journal of the American Society for Information Science, 45, 31-38.

Persson, O. (2008) Bibexcel - A toolbox for bibliometricians. Version 2008-0513, available at http://www8.umu.se/inforsk/Bibexcel/index.html.

Persson, O., Danell, R., Schneider, J. (2009) How to use Bibexcel for various types of bibliometric analysis, in Celebrating scholarly communication studies. Festschrift for Olle Persson, pages 7-24, see especially pages 15-19 for a detailed description of the co-occurrence and mapping analysis followed. Downloaded 17 January 2010 at http://www8.umu.se/inforsk/Bibexcel/ollepersson60.pdf.

Powell, W., and Grodal, S. (2005) Networks of Innovators, in J. Fagerberg, D. Mowery and R. Nelson (Eds.) Oxford Handbook of Innovation, New York: Oxford University Press.

Quigley, J.M. (1998) Urban diversity and economic growth, Journal of Economic Perspectives, 12, 127-138.

Robinson, D.K., Rip, A., and Mangematin, V. (2007) Technological agglomeration and the emergence of clusters and networks in nanotechnology, Research Policy, 36, 871-879.

Saviotti, P., Metcalfe, S. (1991) Present development and trends in evolutionary economics, in Saviotti, P. and Metcalfe, S. (Eds.) Evolutionary Theories of Economic and Technological Change, pp. 1-30: Harwood, Chur.

Saxenian, A. (1994) Regional Advantage: Culture and Competition in Silicon Valley and Route 128 Cambridge, MA: Harvard University Press 
Schmoch, U. (1997) Indicators and the relationships between science and technology, Scientometrics, 38, 103-116.

Shapira, P. and Youtie, J. (2006) Measures for knowledge-based economic development: Introducing data mining techniques to economic developers in the state of Georgia and the US South, Technological Forecasting and Social Change, 73, 950-965.

Shapira, P. and Youtie, J. (2008) Emergence of Nanodistricts in the United States: Path Dependency or New Opportunities?, Economic Development Quarterly 22, 187-199.

Simmie, J. (2005) Innovation and Space: A Critical Review of the Literature, Regional Studies, 39, 789-904.

Wood, S., and Jones, R. (2003) The Social and Economic Challenges of Nanotechnology' Report, Economic and Social Research Council. London. UK

Yli-Renko, H. and Autio, E. (1997) New, Technology-Based Firms, Center for Technology Management . Helsinki Region Center of Expertise, Helsinki University of Technology, Helsinki School of Economics and Business Administration: Working paper,1997|1, 20.

Zitt, M., Barre, R., Sigogneau, A., and Laville, F. (1999) Territorial concentration and evolution of science and technology activities in the European Union: a descriptive analysis, Research Policy, 28, $545-562$.

Zucker, L.G., and Darby, M.R. (2005) Socio-economic Impact of Nanoscale Science: Initial Results and Nanobank, NBER Working Paper 11181, National Bureau of Economic Research. Cambridge, MA. 
Zucker, L.G., Darby, M.R., Furner, J., Liu, R.C., Ma, H. (2007) Minerva unbound: Knowledge stocks, knowledge flows and new knowledge production, Research Policy, 36, 850-863.

${ }^{i}$ Indeed, organizational diversity in the form of new technology-based firms (NTBFs) - new ventures started by independent entrepreneurs - academic spinouts initiated by university scientists-cum-entrepreneurs and large multinational corporations is prevalent in emerging nanoclusters. A case in point is Grenoble, where LETI ( a renowned government electronics laboratory), Thomson Electronics, Motorola and France Telecom, the three local universities making up the University of Grenoble system, the European Synchrotron Facility, Minatec and a host of NTBFs and academic spinouts are co-located and occupy different segments of the nano value chain (Robinson et al, 2007). A similar phenomenon can be observed in Twente, the Netherlands and conceivably around Cambridge and Oxford as we will point out further in this paper.

ii In analogy with Mahdi and Pavitt (1997), one can define a field as 'novel' if it has essentially evolved within the past 20 years.

iii The authors define cross-institutional collaboration and knowledge flows on the basis of co-authored papers (Zucker et al., 2007: 856, fn. 2).

iv http://www.ecoom.be/

$\checkmark$ We have updated the firm population data at the regional level in the autumn of 2009.

${ }^{\text {vi }}$ Persson, O.; Danell, R.; Schneider, J (2009), How to use Bibexcel for various types of bibliometric Analysis. In: Celebrating scholarly communication studies. Festschrift for Olle Persson, pages 7-24, see 
especially pages $15-19$ for a detailed descriptopn of the co-occurrence and mapping analysis followed. Downloaded 17 January 2010 at http://www8.umu.se/inforsk/Bibexcel/ollepersson60.pdf.

vii One issue in determining the degree of proximity between nodes is the question of whether or not to normalise the co/occurrence frequencies. While there are good reasons in favour of this approach (see e.g. Leydesdorff, 2008), we chose the standard approach drawing on frequency data without normalising it.

viii The location of the nodes on the maps cannot be modified substantially without obscuring the co-occurrence based networks. For instance, moving overseas localities to one side of the map and domestic ones to the other may offer a clearer picture as to activities within the UK and elsewhere. However, this would essentially run against the underlying idea of presenting nodes in a two dimensional space that reflects the strengths of their relationships to each other.

${ }^{\text {ix }}$ In other countries, such as Germany, the share of nano-inventors amongst nano-scientists is higher (around 1.5\%) but still very low.

${ }^{x}$ For purposes of comparison, the value for Germany is 34\% (Meyer 2006)

${ }^{x i}$ This corresponds to the approach by Gilsing et al (2008) who define technological distance as the average of correlations between a focal firm's technology profile and that of each of its collaboration partners, a measure of similarity in technological knowledge and application domains of partners. xii We used Persson's (1994) clustering algorithm in the Bibexcel bibliometric analysis freeware to analyze collaborative links. 


\section{Figures}

Figure Error! Main Document Only. Distribution of Publication Activity Across UK Regions

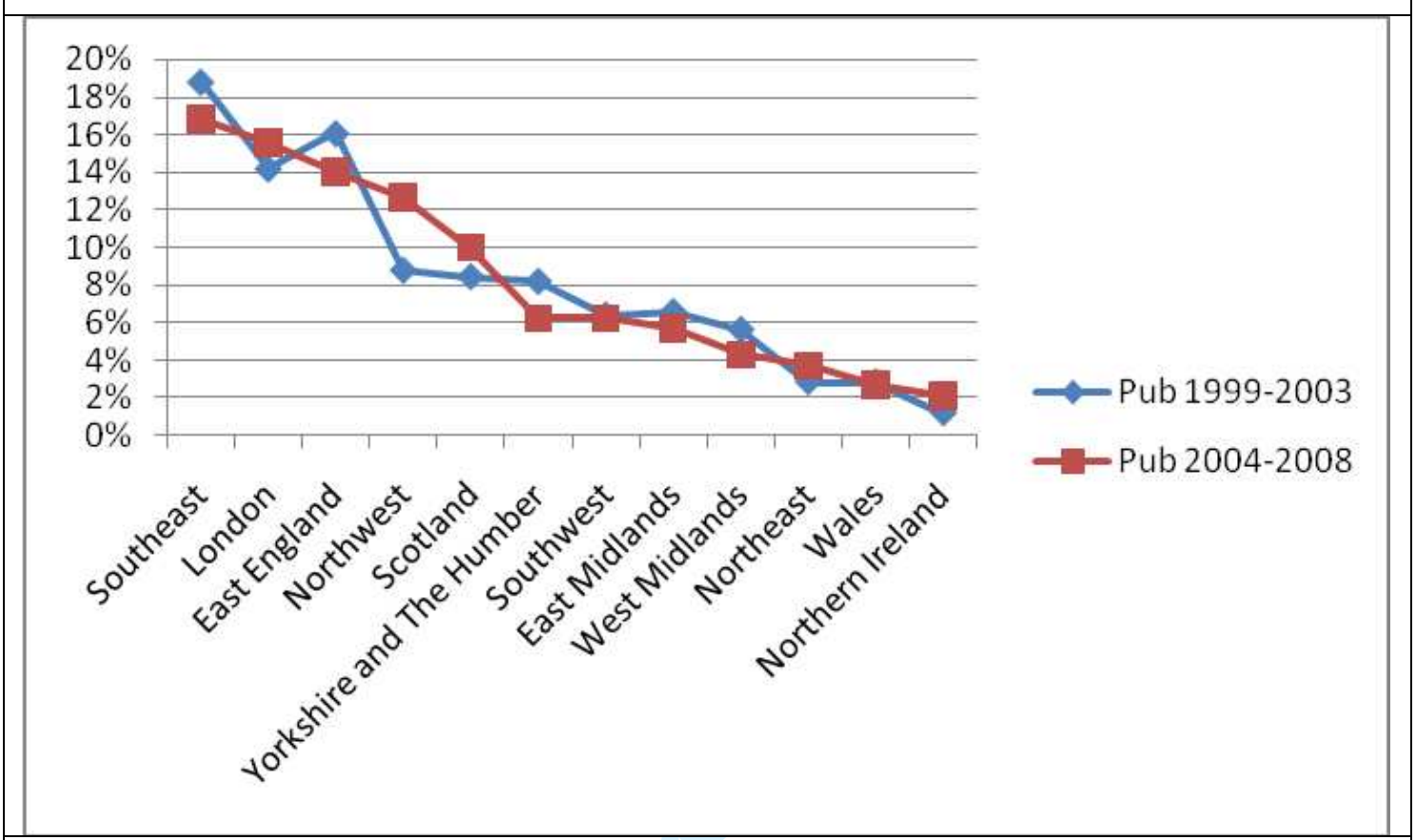

Figure Error! Main Document Only. Distribution of Patenting Activity Across UK Regions

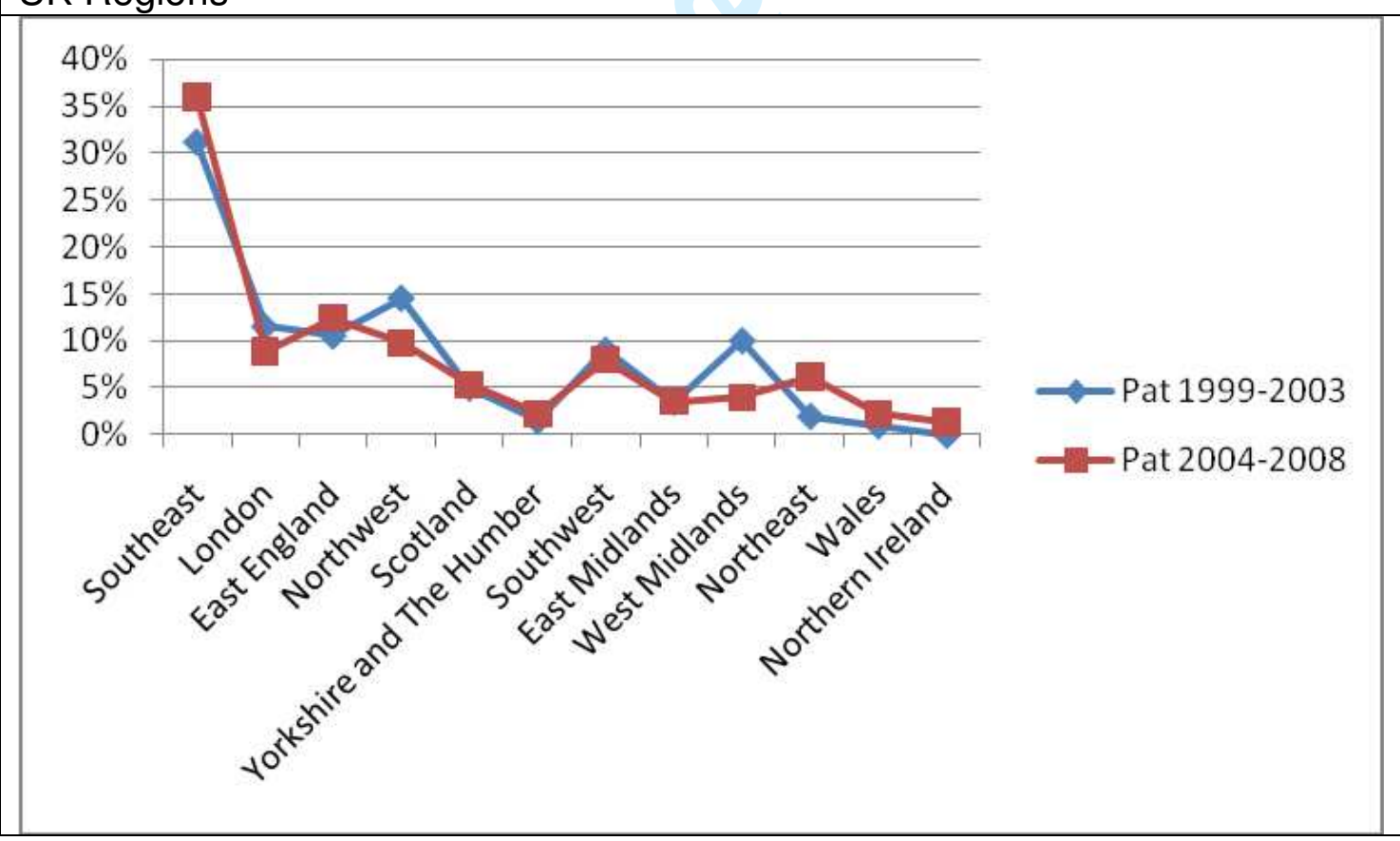


Figure Error! Main Document Only. Distribution of Nanotechnology-related Firms across UK regions

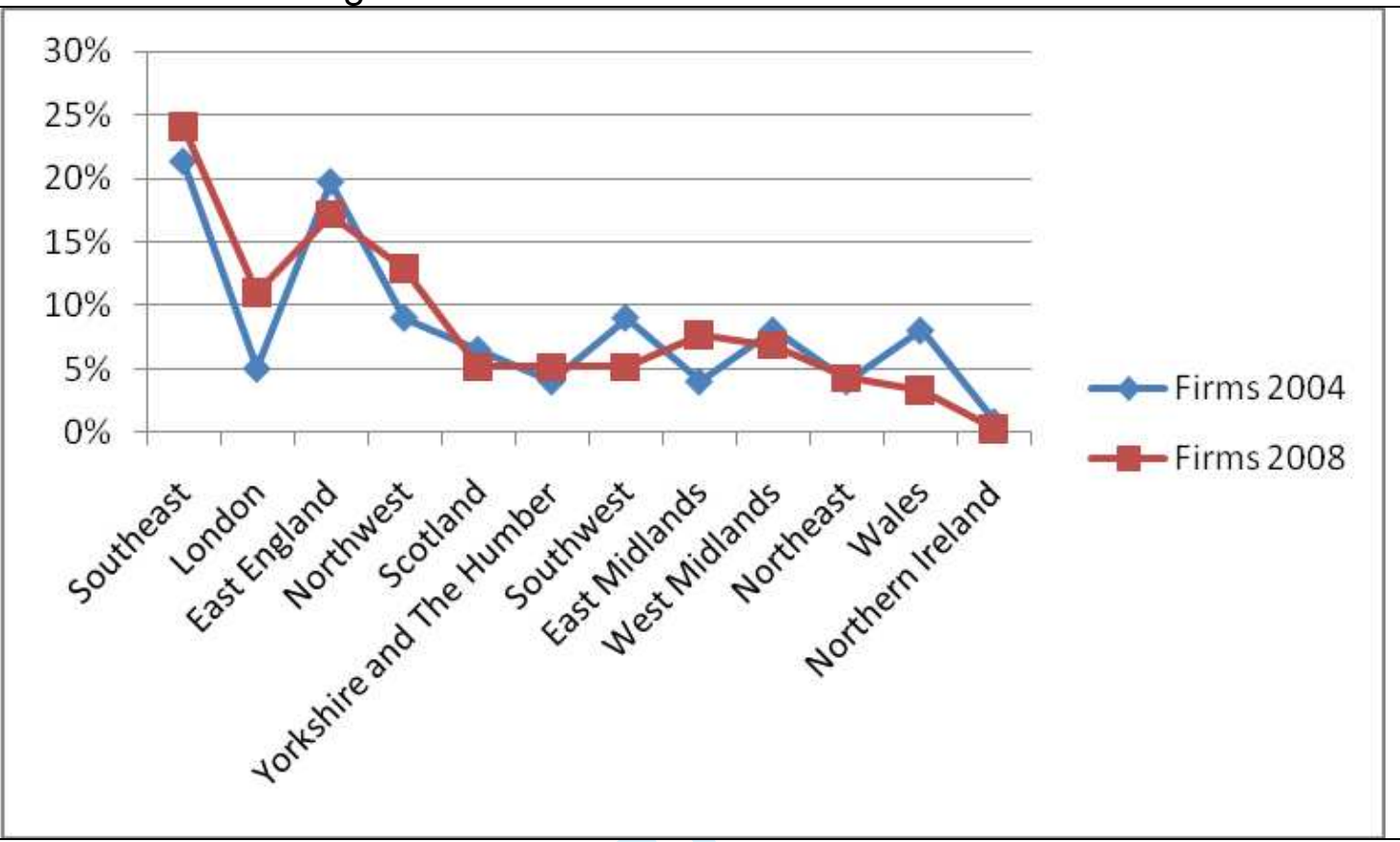

Figure Error! Main Document Only. Comparison of Regional Distributions 1999-2008:

Publications, Patents, and Firms

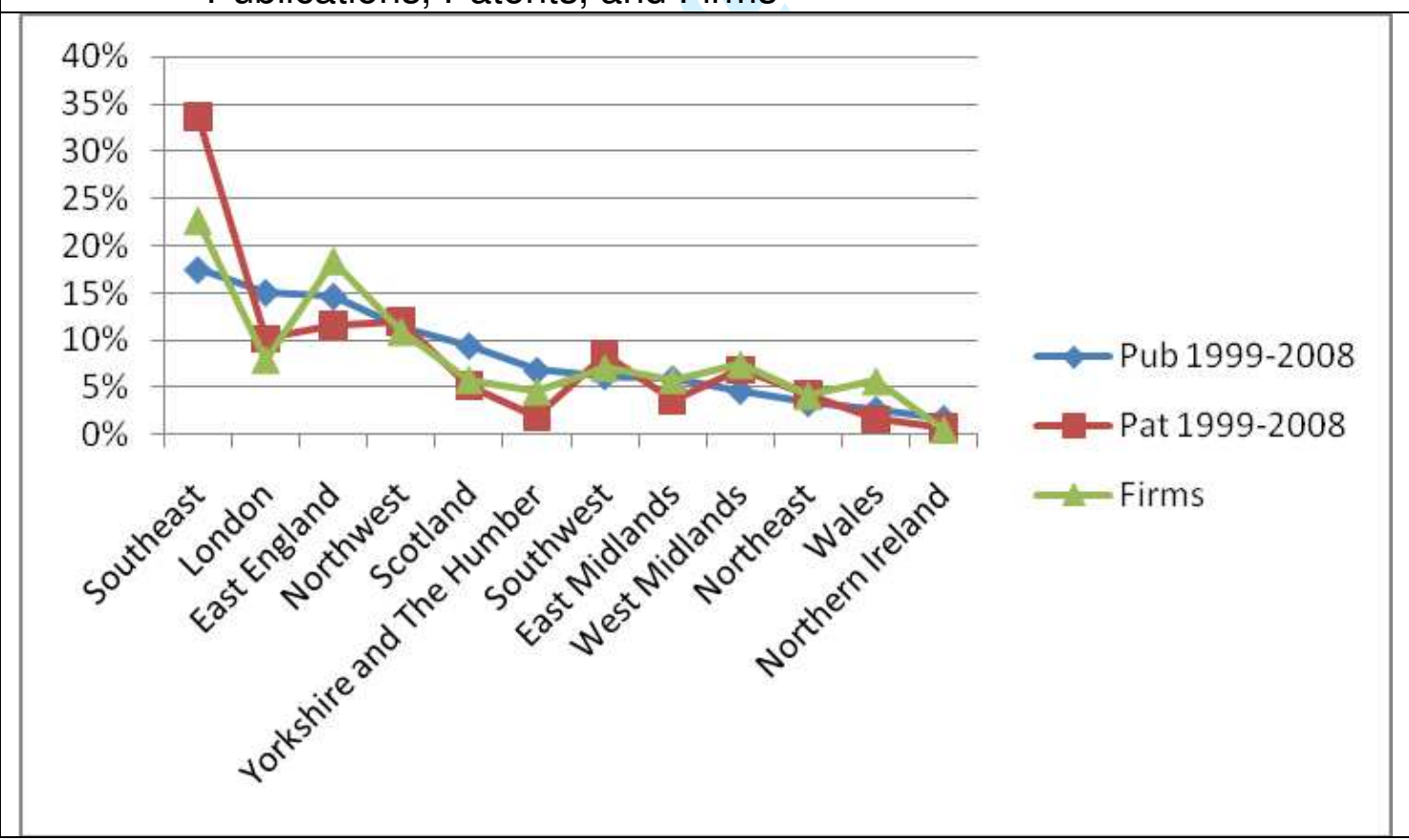


Figure Error! Main Document Only. Collaboration in UK nano-science 1999-2003

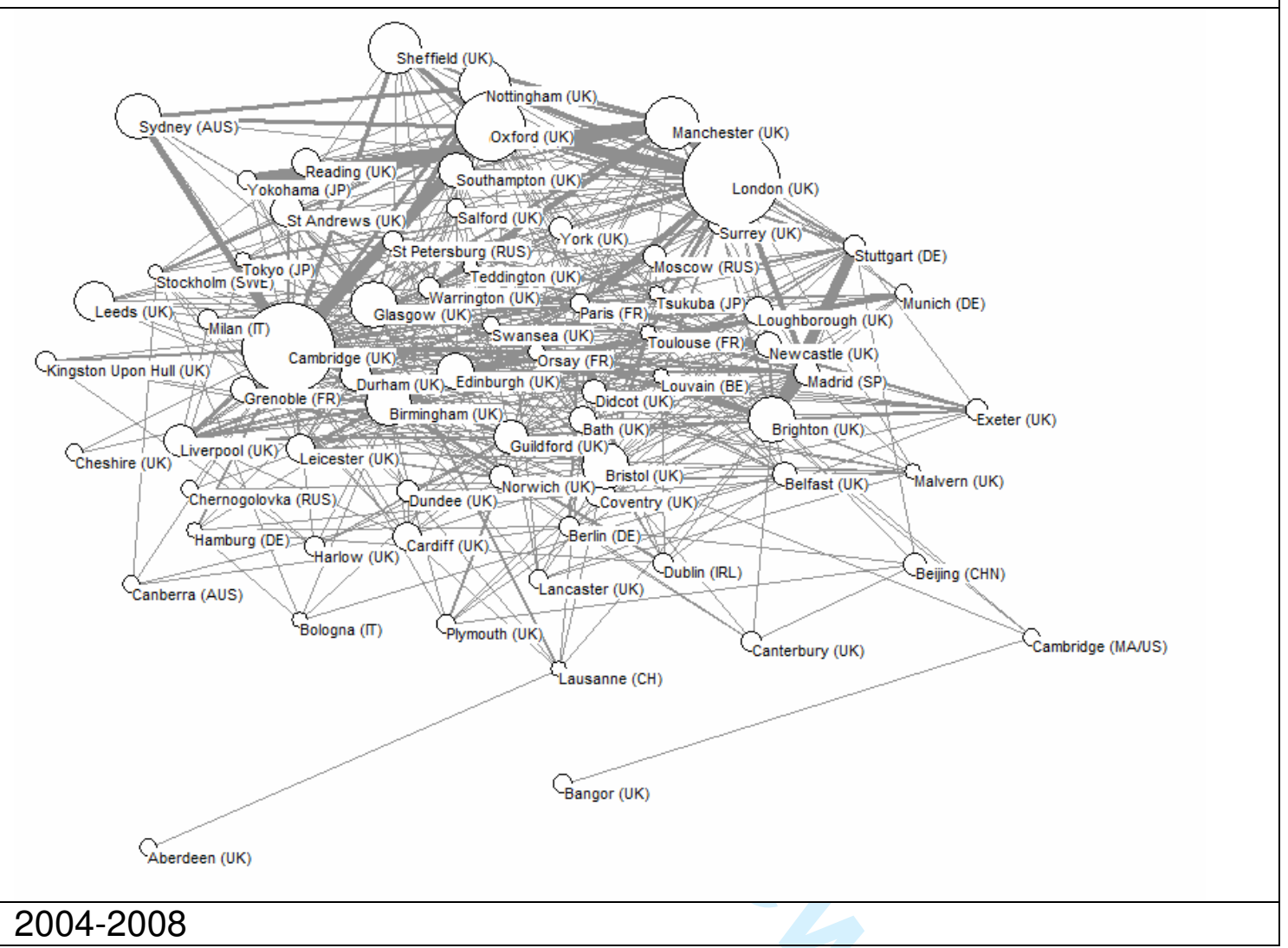




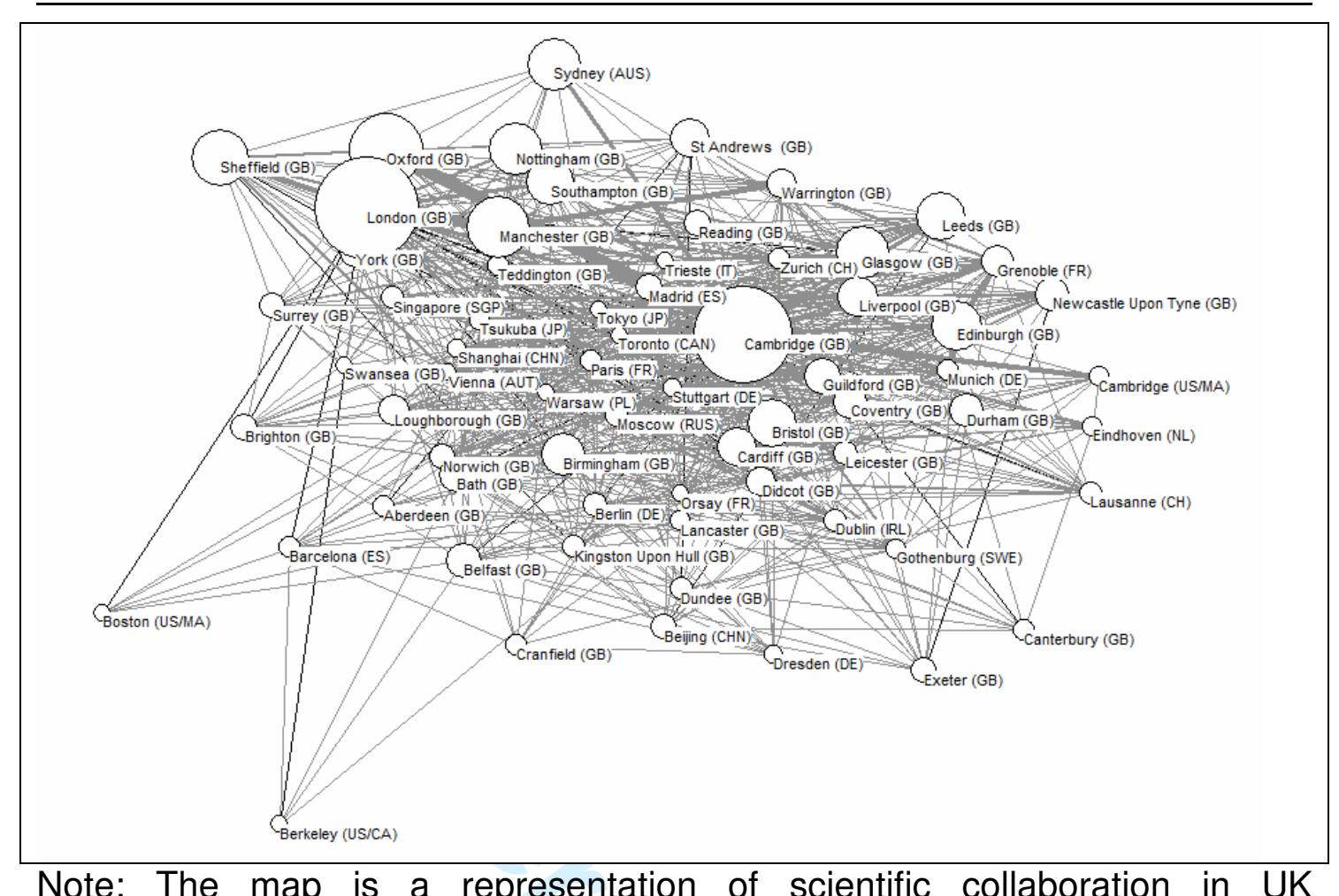

Note: The map is a representation of scientific collaboration in UK nanoscience. Circle size indicates the publication frequency while thickness of links between circles indicates the strength of co-publication links. Labels are placed in the lower right quarter of the circle they are associated with. Sometimes circles overlap or hide other locations. 
Figure Error! Main Document Only. Domestic Collaboration in UK nanoscience (by regions)

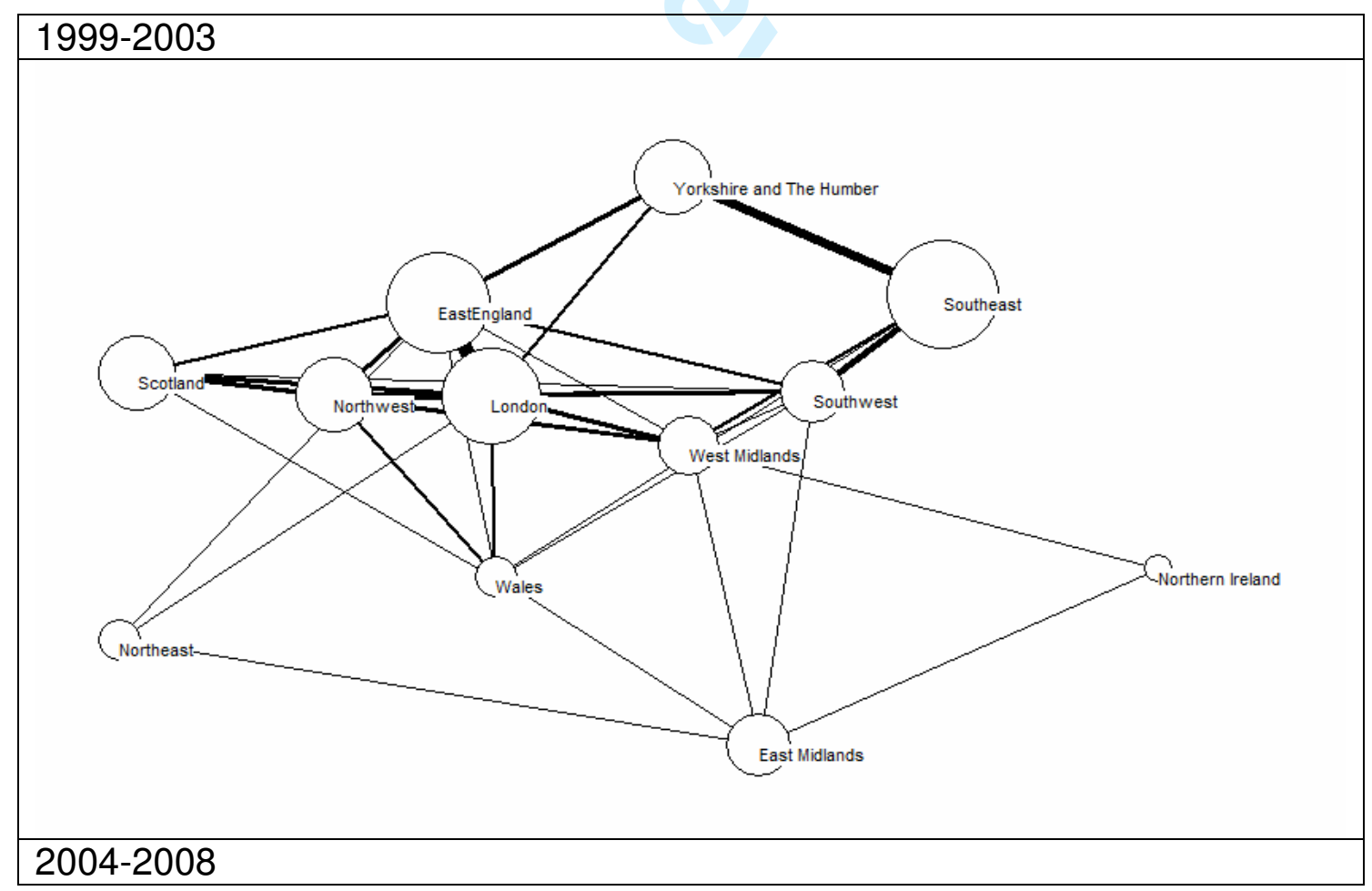




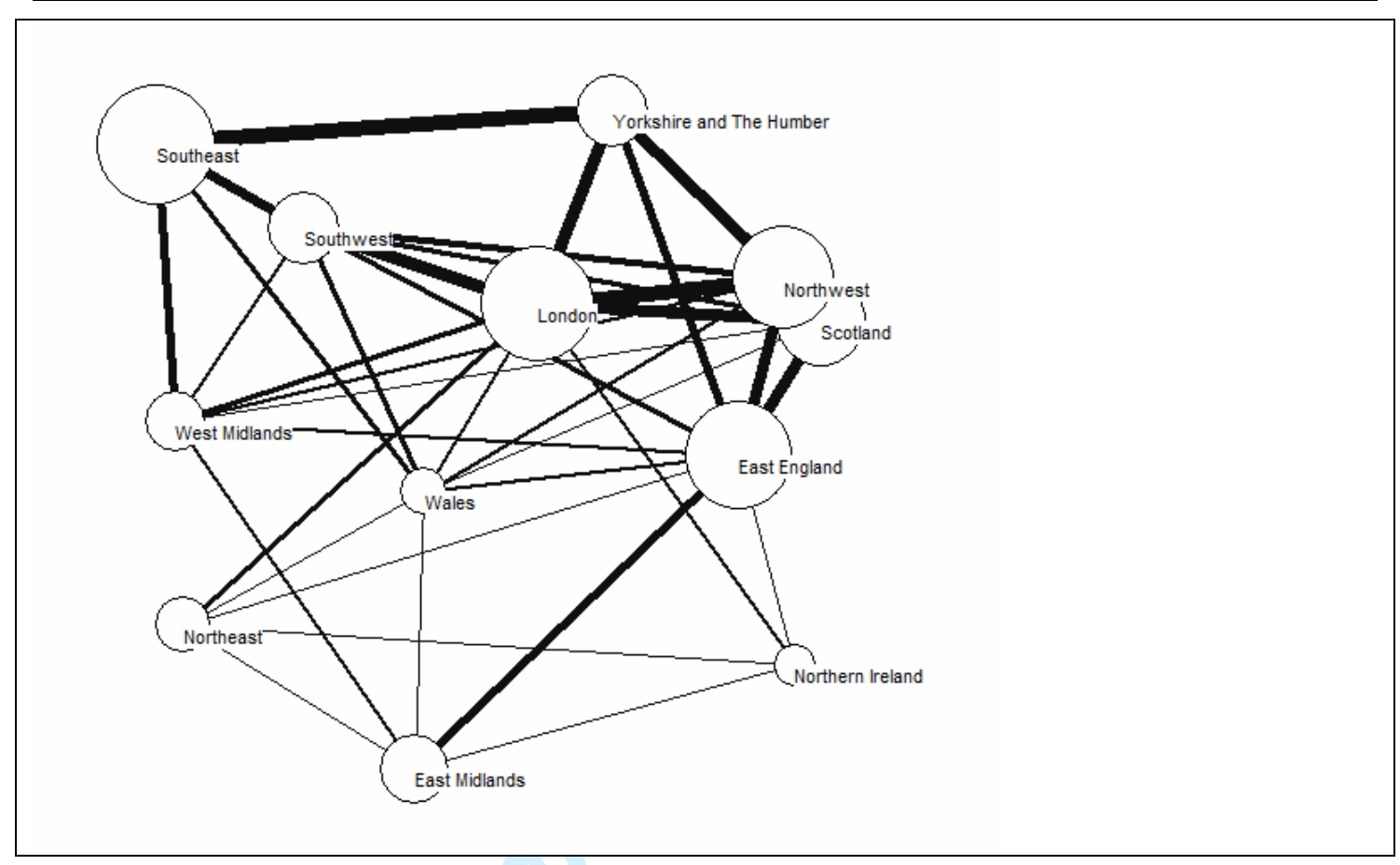

Note: The map is a representation of domestic scientific collaboration in UK nanoscience. Circle size indicates the publication frequency while thickness of links between circles indicates the strength of co-publication links.

Figure Error! Main Document Only. Collaboration in UK nano-patenting $1999-2003$ 


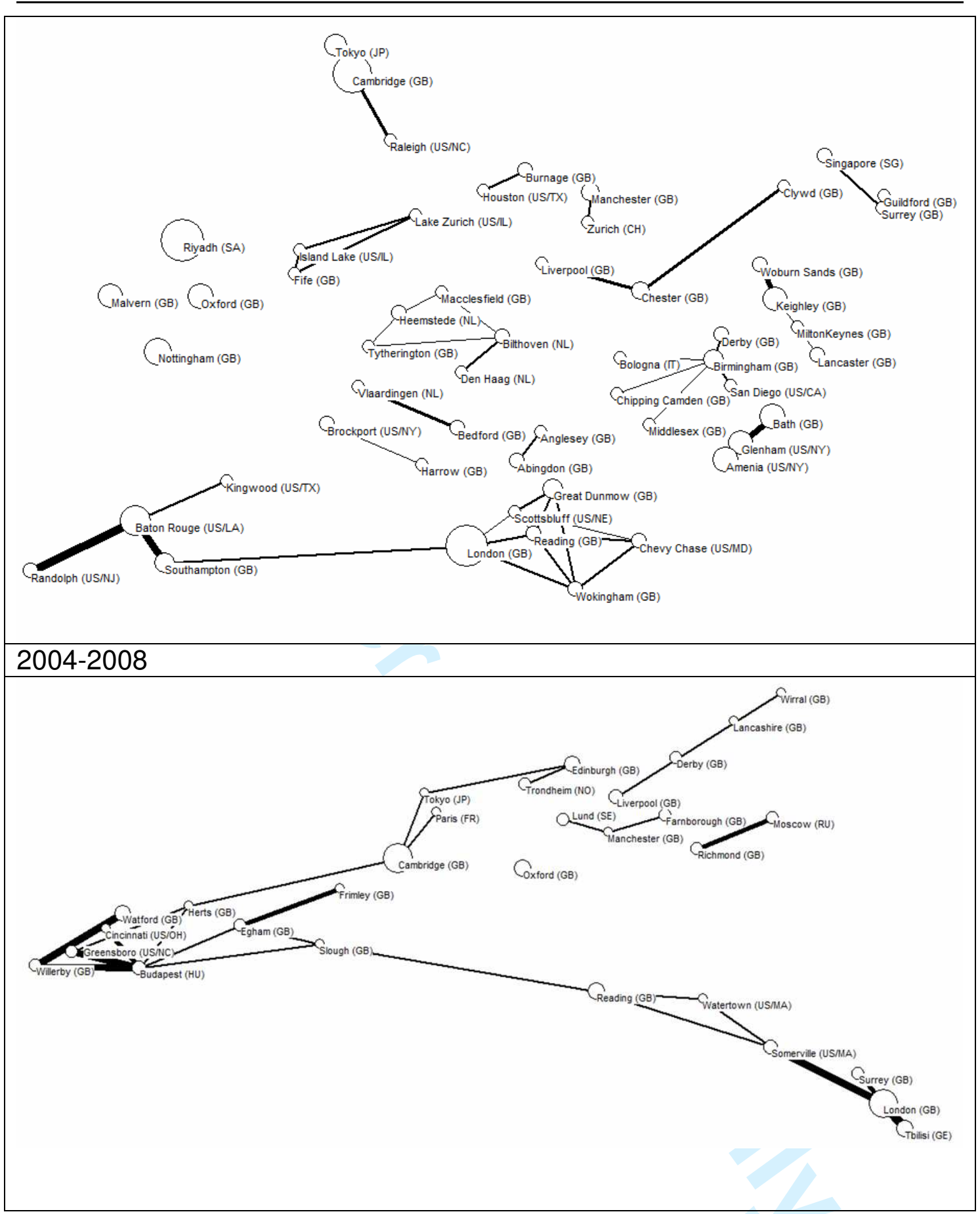

Note: The map is a representation of cognitive links on the basis of copatenting activity at the level of localities. Circle size indicates output while thickness of links between circles indicates the strength of co-patent links.

Figure Error! Main Document Only.. Co-classification links in UK nano-patenting 1999-2003 


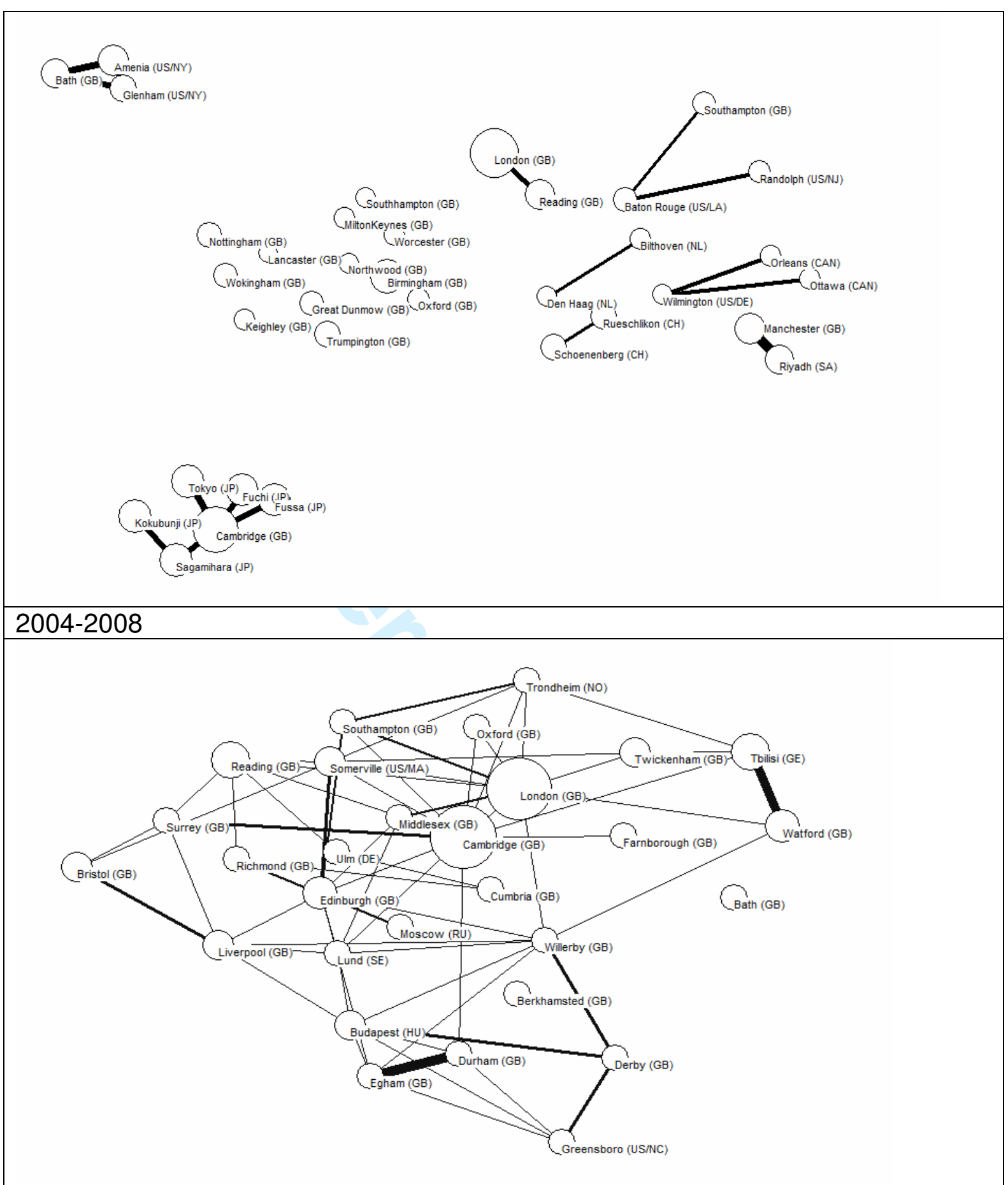

Note: The map is a representation of cognitive links on the basis of shared patent classifications ('co-classifications') at the level of localities. Circle size indicates the co-classification frequency while thickness of links between circles indicates the strength of co-classification links. Readers may compare co-invention with co-classification maps and note that some locations may have 'dropped off' the map while others appear. This is due to the thresholds 
that are applied to co-invention and co-classification data. A high level of collaborative patent activity in a narrow area of technology may not coincide with technological breadth as documented by multiple classifications.

Similarly, links can result from relatively low levels of co-inventive activity that seeks to integrate technologies across a comparatively wide range (illustrated by patent classifications).

Figure 9 Cluster membership by UK Region (counts of nano-members) 


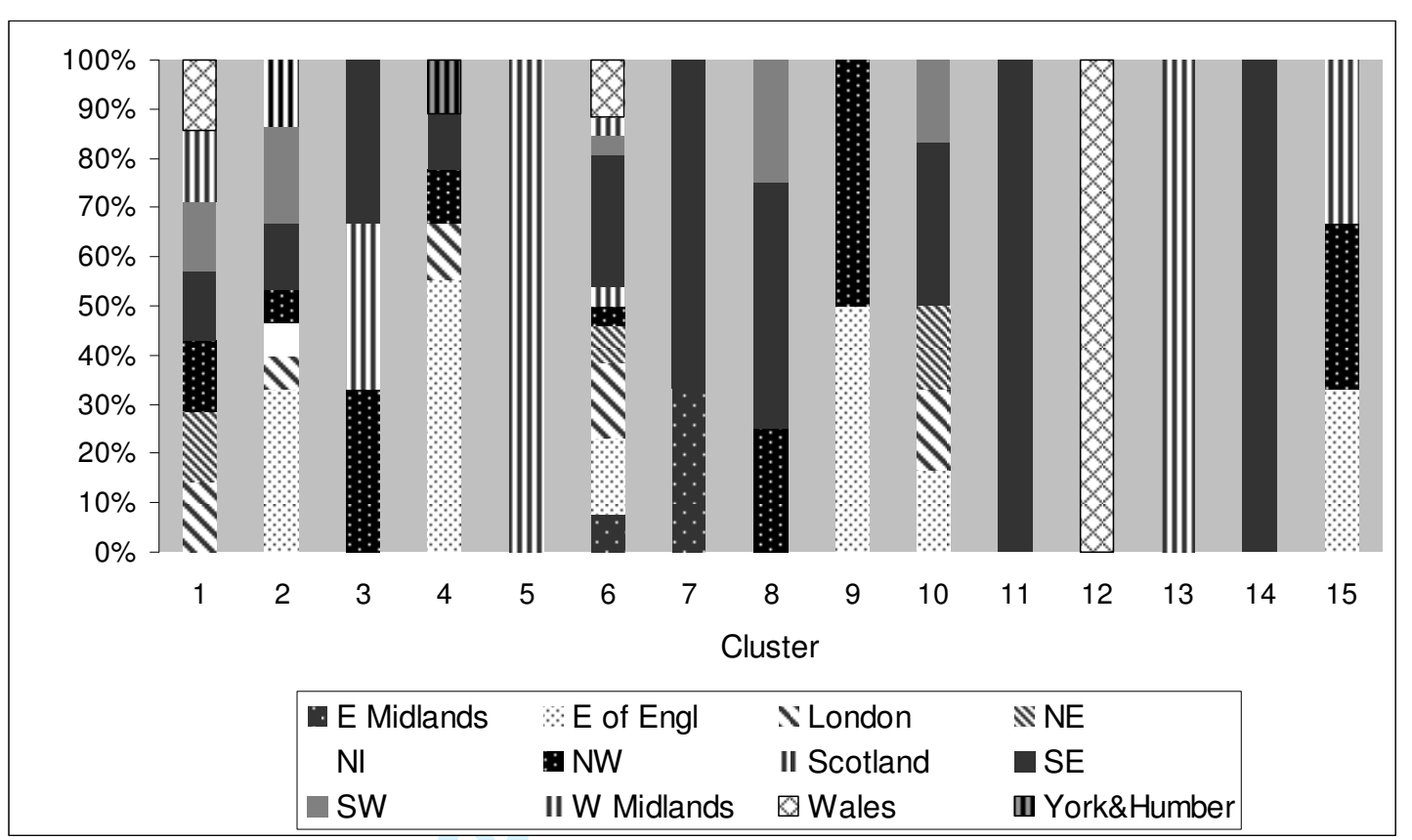

Figure 10 Cluster membership by firm type 


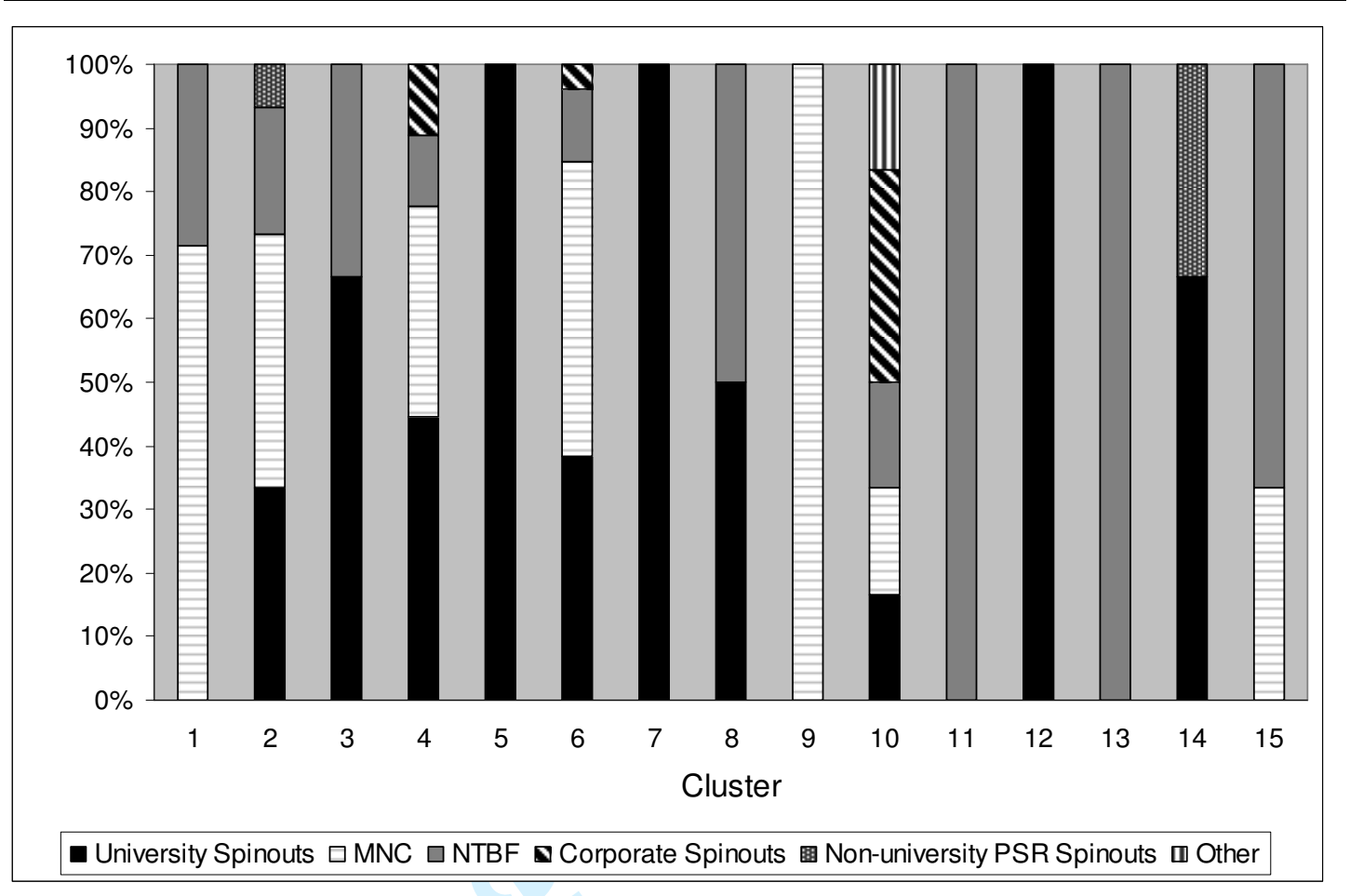

Tables 
Table 1. Occurrence of local co-invention links: Patent data for 1999-2003

\begin{tabular}{|l|c|c|c|c|}
\hline Town/County & $\begin{array}{c}\text { Share of } \\
\text { Local } \\
\text { Collaboration } \\
\text { s }\end{array}$ & $\begin{array}{c}\text { All } \\
\text { Collaboration } \\
\text { s }\end{array}$ & $\begin{array}{c}\text { Local } \\
\text { Collaboration } \\
\text { s }\end{array}$ & $\begin{array}{c}\text { Specialisatio } \\
\mathrm{n}^{*}\end{array}$ \\
\hline Cambridge & $22 \%$ & 50 & 11 & $38 \%$ \\
(GB) & $18 \%$ & 22 & 4 & $32 \%$ \\
London (GB) & $20 \%$ & 10 & 2 & $35 \%$ \\
Keighley (GB) & $30 \%$ & 10 & 3 & $52 \%$ \\
Malvern (GB) & $88 \%$ & 8 & 7 & $152 \%$ \\
Oxford (GB) & $43 \%$ & 7 & 3 & $74 \%$ \\
Nottingham & $100 \%$ & 7 & 7 & $174 \%$ \\
(GB) & $50 \%$ & 6 & 3 & $87 \%$ \\
Derby (GB) & $100 \%$ & 6 & 6 & $174 \%$ \\
Haslar (GB) & $20 \%$ & 5 & 1 & $35 \%$ \\
Bedford (GB) & $20 \%$ & 5 & 1 & $35 \%$ \\
Guildford (GB) & $20 \%$ & 5 & 1 & $35 \%$ \\
Lancaster (GB) & & & & \\
Southampton & $33 \%$ & 3 & 1 & $174 \%$ \\
(GB) & $100 \%$ & 1 & 1 & $174 \%$ \\
Dundee (GB) & $100 \%$ & 1 & 1 & \\
Riccarton (GB) & $10 \%$ & & \\
\hline
\end{tabular}

* Defined as share of local links divided by average share

Table 2. Occurrence of local co-invention links: Patent data for 2004-2008 


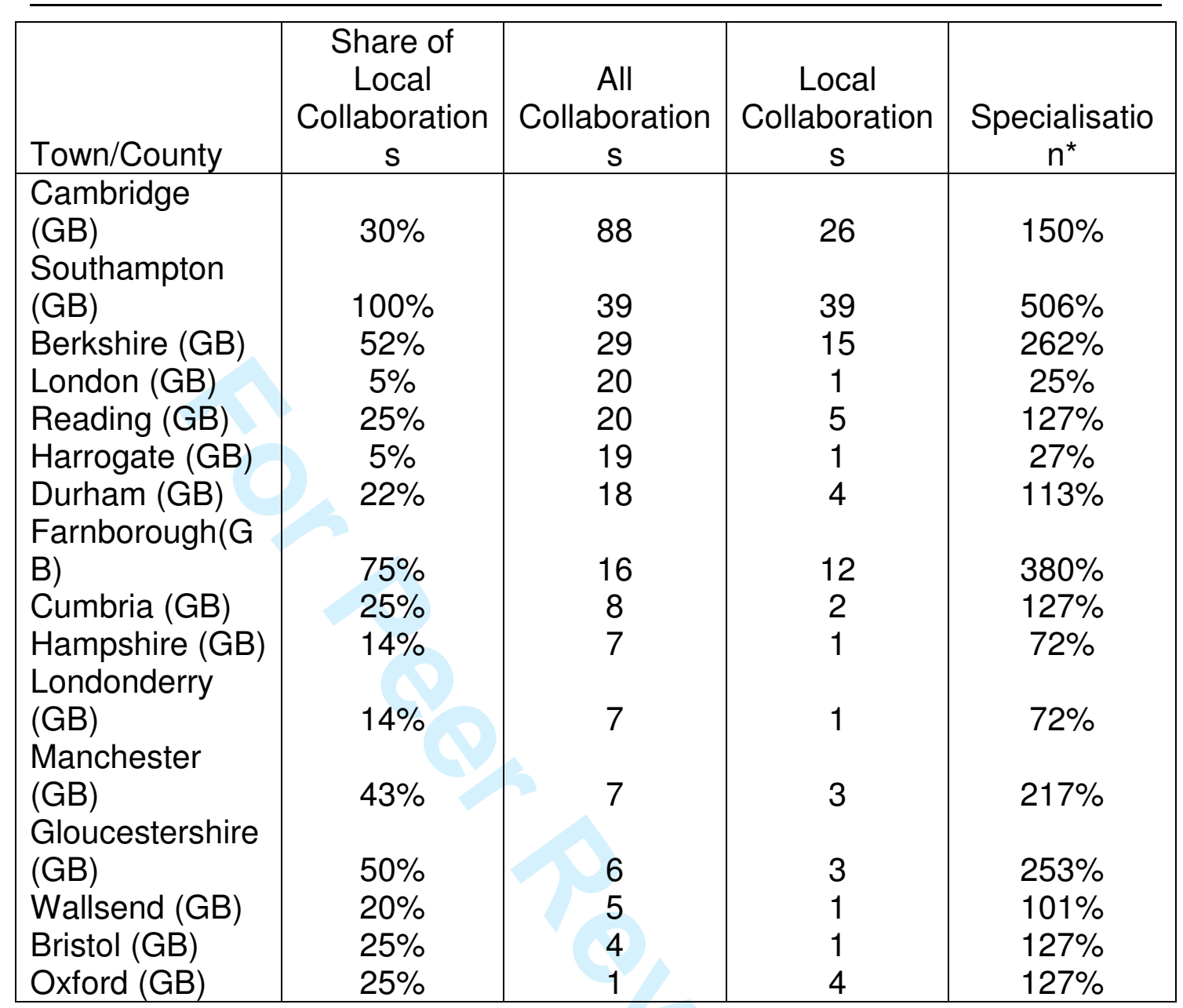

* Defined as share of local links divided by average share

Table 3. Breadth of technology development at town level: Patent classes associated with towns/regions

\begin{tabular}{|ll|lc|}
\hline $\begin{array}{l}\text { 1999-2003 } \\
\text { Town }\end{array}$ & $\begin{array}{l}\text { 2004-2008 } \\
\text { Town }\end{array}$ & Count \\
\hline
\end{tabular}




\begin{tabular}{|c|c|c|c|}
\hline London (GB) & 180 & London (GB) & 233 \\
\hline $\begin{array}{l}\text { Cambridge } \\
\text { (GB) }\end{array}$ & 151 & Cambridge (GB) & 210 \\
\hline $\begin{array}{l}\text { Manchester } \\
\text { (GB) }\end{array}$ & 83 & Oxford (GB) & 124 \\
\hline $\begin{array}{l}\text { Birmingham } \\
\text { (GB) }\end{array}$ & 69 & Reading (GB) & 84 \\
\hline Bath (GB) & 48 & Edinburgh (GB) & 74 \\
\hline Oxford (GB) & 45 & Durham (GB) & 67 \\
\hline $\begin{array}{l}\text { Nottingham } \\
\text { (GB) }\end{array}$ & 40 & $\begin{array}{l}\text { Manchester } \\
\text { (GB) }\end{array}$ & 57 \\
\hline Keighley (GB) & 38 & Middlesex (GB) & 52 \\
\hline Reading (GB) & 34 & $\begin{array}{l}\text { Farnborough } \\
\text { (GB) }\end{array}$ & 51 \\
\hline $\begin{array}{l}\text { Middlesex } \\
\text { (GB) }\end{array}$ & 33 & $\begin{array}{l}\text { Berkhamsted } \\
\text { (GB) }\end{array}$ & 50 \\
\hline Average & 18.25 & Average & 21.70 \\
\hline
\end{tabular}

Table 4 Collaborative Clusters of UK Nanotech Firms 


\begin{tabular}{|c|c|c|c|c|c|c|}
\hline Cluster & $\mathbf{N}$ & n (nano, UK) & [in \%] & n (univ) & [in \%] & Focus \\
\hline 1 & 14 & 6 & $43 \%$ & 7 & $50 \%$ & Nanomaterials \\
\hline 2 & 39 & 16 & $41 \%$ & 12 & $31 \%$ & Nanodevices/materials \\
\hline 3 & 6 & 3 & $50 \%$ & 3 & $50 \%$ & Nanomaterials/instruments \\
\hline 4 & 19 & 9 & $47 \%$ & 6 & $32 \%$ & Nanoinstruments/electronics \\
\hline 5 & 3 & 1 & $33 \%$ & 2 & $67 \%$ & Nanomaterials \\
\hline 6 & 55 & 26 & $47 \%$ & 10 & $18 \%$ & Nanomaterials/instruments \\
\hline 7 & 5 & 3 & $60 \%$ & 2 & $40 \%$ & Nanodevices \\
\hline 8 & 7 & 4 & $57 \%$ & 3 & $43 \%$ & Nanobio/devices \\
\hline 9 & 11 & 2 & $18 \%$ & 5 & $45 \%$ & Nanodevices/materials \\
\hline 10 & 16 & 6 & $38 \%$ & 5 & $31 \%$ & Nanodevices \\
\hline 11 & 5 & 1 & $20 \%$ & 0 & $0 \%$ & Nanoinstruments \\
\hline 12 & 4 & 1 & $25 \%$ & 1 & $25 \%$ & Nanoinstruments \\
\hline 13 & 3 & 1 & $33 \%$ & 2 & $67 \%$ & Nanoinstruments \\
\hline 14 & 9 & 3 & $33 \%$ & 3 & $33 \%$ & Nanodevices/materials/photonics \\
\hline 15 & 6 & 3 & $50 \%$ & 2 & $33 \%$ & Nanomaterials/instruments \\
\hline
\end{tabular}

